\title{
UNA BREVE DISERTACIÓN SOBRE LOS VALDENSES DE JOSEP MERCADER (1764)
}

\author{
POR \\ SERGi Grau Torras \\ Licenciado en Historia (UAB)
}

\section{RESUMEN}

En 1764 el dominico y académico Josep Mercader escribió una breve disertación sobre los valdenses. El autor describe la aparición de esta herejía en Cataluña, presenta distintas hipótesis sobre el origen del término valdense y finaliza el recorrido con la fusión de esta herejía con los protestantes en el siglo XVI. Josep Mercader proporciona información relevante sobre la historia de la valdesía a través del uso de fuentes documentales de la época.

PALABRAS ClAVE: valdenses, Josep Mercader, herejía

\section{A BRIEF DISSERTATION ON WALDENSES BY JOSEP MERCADER (1764)}

\section{ABSTRACT}

In 1764 the Dominican and academic Josep Mercader wrote a short dissertation on Waldenses. The author describes the appearance of this heresy in Catalonia, he presents also different hypotheses about the origin of Waldensian term and he finishs his dissertation with the merger of this heresy with Protestants in the XVIth century. Josep Mercader provides relevant information about the Waldensian history using documentary sources from his time.

KEY WORDS: Waldenses, Josep Mercader, heresy

Recibido/Received 2010-09-21

Aceptado/Accepted 2011-06-24 
La Disertación primera del error o herejía de los enzapatados, ${ }^{1}$ es un breve opúsculo que forma parte de las Disertaciones historico-eclesiasticas que escribió Josep Mercader a mediados del siglo XVIII. Josep Mercader fue un dominico que llegó a ser prior y regente de estudios del convento de Santa Caterina de Barcelona. ${ }^{2}$ En 1743 cuando era prior del convento, encargó al bibliotecario Pere Màrtir Angles que continuara el Lumen Domus o Annals del convent de Santa Caterina de dos volúmenes que había iniciado Francesc Camprubí el siglo anterior. ${ }^{3}$ Mercader fue también miembro de la Academia de las Buenas Letras de Barcelona desde el 26 de mayo de $1731 .{ }^{4}$ En 1757 fue nombrado revisor de historia ${ }^{5}$ y el 13 de enero de 1779 presidió una Junta General como decano. ${ }^{6}$ El 14 de julio de ese mismo año se anunciaba su muerte en el Boletín de la Real Academia. ${ }^{7}$ A lo largo de su vida escribió varios textos entre los que se encuentra la Oracion funebre que en las exequias dedicadas por la Real Academia de Buenas Letras de la ciudad de Barcelona del 20 de diciembre de $1755 .{ }^{8}$

El 8 de enero y el 5 de noviembre de 1755 Josep Mercader presentó en la Academia de las Buenas Letras de Barcelona una disertación sobre las herejías y supersticiones en la historia de España y Cataluña. ${ }^{9}$ El 4 de julio de 1764, Mercader presentaba en la Junta General «doce disertaciones sobre las heregías y supersticiones que corrían en España en los siglos VII y VIII y lee otra sobre

\footnotetext{
${ }^{1}$ Abreviaturas: Fondo de Reserva de la Biblioteca Universitària de Barcelona (BU); Monumenta Germaniae Historica (MGH), Mansi, J. D. (ed.) 1759-1792. Sacrorum Conciliorum Nova Amplissima Collectio, 53 vols. Florencia-Venecia (Mansi); Gonnet, G. (ed.) 1958. Enchiridion fontium valdensium 1, Du IIIe Concile de Latran au Synode de Chanforan (1179-1532) Torre Pellice: Claudiana (EFV); Migne, J. P. (ed.) 1844-1855. Patrologiae Latinae, 271 vols. París, reed. Turnholti, Brepols, 1970 (PL); Rius Serra, J. 1954. San Raimundo de Penyafort. Diplomatario, Documentos, Cartas de San Raimundo de Penyafort, de Gregorio IX y de varios autores. Vida antigua, Crónicas, Procesos antiguos Barcelona (Diplomatario). El opúsculo sobre los valdenses lleva por título Disertación primera del error o herejia de los enzapatados y se conserva en el manuscrito 837 del Fondo de Reserva de la Biblioteca Universitaria de Barcelona, Joseph Mercader OP, Disertaciones historico-eclesiasticas, folios 21r-26v (=Disertaciones). Escrito en castellano y a mano el texto contiene formas gramaticales catalanas e integra algunas citas latinas. Para las citas hemos adaptado el texto a la grafía moderna.

${ }^{2}$ Campabadal, M. 2006. La Reial Acadèmia de Bones Lletres de Barcelona en el segle XVIII: l'interès per la història, la llengua i la literatura catalanes Barcelona: Reial Acadèmia de Bones Lletres de Barcelona; Publicacions de l'Abadia de Montserrat (Textos i Estudis de Cultura Catalana, 119): 385.

${ }^{3}$ PP. Francesch Camprubí, Pere Màrtir Angles OP, Lumen Domus o Anals del Convent de Santa Catarina, Tom I des de l'any 1219 fins 1634 inclusive, 1743, fol. 1, BU, ms. 1005.

${ }^{4}$ Boletin de la Real Academia de las Buenas Letras de Barcelona, volúmen 9, año 17, num 65, 1917, 15. Los textos de las noticias los presenta Joaquim Miret y Sans.

${ }^{5}$ Ibídem, 92.

${ }^{6}$ Ibídem, 109.

${ }^{7}$ Ibídem, 110.

${ }^{8}$ Joseph Mercader, Oración funebre que en las exequias dedicadas por la Real Academia de Buenas Letras de la ciudad de Barcelona, el dia 20 de Diciembre de 1755, en el templo de Santa Cathalína martyr de la misma ciudad, a la memoria de su presidente el ... Conde de Perelada, dixo ... fr. Joseph Mercadèr, Barcelona en la imprenta de Francisco Surià, 1756.

${ }^{9}$ Campabadal, M. 2006: 144-145.
}

Hispania Sacra, LXIV

129, enero-junio 2012, 279-307, ISSN: 0018-215-X, doi: 10.3989/hs.2012.010 
la heregía "llamada de los enzapatados ó falsos santurrones en Cataluña"». ${ }^{10} \mathrm{El}$ texto de la lectura sobre los enzapatados de 1764 es la Disertación primera del error o herejía de los enzapatados que presentamos a continuación. ${ }^{11}$

La disertación sobre los «enzapatados», nombre con el que fue conocida la herejía de los valdenses, centra su atención en la historia de la valdesía desde el siglo XII hasta el siglo XVI. ${ }^{12}$ Mercader destaca su presencia en el Principado de Cataluña, presenta distintas hipótesis sobre el origen del término Valdés y termina con la fusión de esta herejía con los protestantes. A través de su análisis podemos constatar la importancia del contenido y el número de fuentes que consultó. Además, este documento ofrece elementos para comprender la mentalidad de escritores religiosos de la época frente al problema de la herejía.

\section{SOBRE EL ORIGEN DE LOS ERRORES}

El autor escribe este opúsculo para «inquirir las herejías que hallaron lugar en España y principalmente aquellas que fijaron su raíz en este Principado». ${ }^{13}$ Su trabajo se propone empezar en el siglo VIII con la herejía del adopcionismo.

«De este siglo la primera y más verificada herejía es la de Feliu obispo de Urgell, el cual, interrogado de Elipando, obispo de Toledo, cual era su distinto orden a la filiación de Jesucristo le respondió conforme al error [...] Hallándose en el mismo dictamen estos dos obispos comenzaron en el año 792 a sembrar superstición y a engañar... que nuestro señor aunque es hijo natural de Dios Padre según la naturaleza divina lo es también adoptado según la humana. ${ }^{14}$ [...] Dejando pues en su condenación estos errores y los que en el año 794 expuso el concilio de Francfort [...] contra su pertinacia reprodujo el de Aquisgrán en el año $799^{15}$ [...] Procuraron ambos prelados a propagar la perversidad de su dogma inficionando el de Toledo a las Asturias y Galicia, mientras el de Urgel hizo lo mismo por toda la Septimania». ${ }^{16}$

\footnotetext{
${ }^{10}$ Boletin de la Real Academia, 1917: 98.

${ }^{11}$ Disertaciones, f. $26 \mathrm{r}$.

${ }^{12}$ Existe una importante producción historiográfica sobre los valdenses. Mencionamos a título general: Cahiers de Fanjeaux, núm. 2: «Vaudois languedociens et pauvres catholiques», Tolouse 1967; Gonnet, G. (ed.) 1958; Gonnet, G. (ed.) 1998. Enchiridion fontium valdensium 2, De la fin du XII $a u$ début du XIVe siècle Torino: Claudiana, 1998; Gonnet, G., Molnar, A. 1974. Les vaudois au moyen age Torino: Claudiana; Benedetti, M. 2007. Donne valdesi nel medioevo Torino: Claudiana; Biller, P. 2001. The waldenses 1170-1530: between a religious order and a church Aldershot: Ashgate; Papini, C. 2001. Valdo di Lione e $i$ "poveri nello spirito» Torino: Claudiana; Cameron, E. 2001. Waldenses: Rejections of Holy Church in Medieval Europe Oxford: Blackwell Publishers. Centrado en Cataluña el trabajo de Ventura, J. 19611962. «La valdesía de Cataluña». Boletín de la Real Academia de las Buenas Letras de Barcelona 29: 275-317.

${ }^{13}$ Disertaciones, f. $21 \mathrm{r}$.

${ }^{14}$ Disertaciones, f. $21 \mathrm{v}$.

${ }^{15}$ Disertaciones, f. $22 \mathrm{r}$.

${ }^{16}$ Disertaciones, f. $21 \mathrm{v}-22 \mathrm{r}$.
} 
El primer error al que alude Mercader es el adopcionismo que designaba la confluencia de la naturaleza divina y la naturaleza humana en un mismo cuerpo. ${ }^{17}$ Esta doctrina apareció a finales del siglo VIII y sus representantes fueron Félix de Urgell, Elipando de Toledo y Claudio de Turín.

En este breve párrafo el autor informa de los acontecimientos fundamentales que giraron en torno a Félix y Elipando. El contacto entre ambos prelados quedó reflejado en los Anales Francos a través de la consulta (litteras consultus) a la que se refiere Mercader en su texto. ${ }^{18} \mathrm{El}$ autor sitúa el año 792 como el inicio de la predicación del adopcionismo, sin referirse directamente al concilio de Ratisbona que tuvo lugar el mismo año. El concilio de Ratisbona condenó la doctrina de Félix que se desplazó a Roma poco después para presentarse ante el papa Adriano I. ${ }^{19}$ Los concilios que menciona Mercader son el de 794 en Frankfurt, que fue consecuencia de las cartas que los obispos hispánicos escribieron a Carlomagno para pedir su intercesión en el caso, y el concilio de Aquisgrán celebrado en el $799 .{ }^{20}$ Con ello, Mercader contextualiza tres momentos determinantes en el proceso contra el adopcionismo y destaca los espacios de difusión de esta herejía en Asturias, Galicia y la Septimania. Después de la breve mención del adopcionismo, el autor centra su atención en las herejías del siglo XII.

Estas son «las que abrazaron nuestros paysanos conocidas con el nombre de enzapatados a quienes Alfonso rey de Aragón y conde de Barcelona destruyó de todos sus dominios en el año 1194».21

\footnotetext{
${ }^{17}$ Algunos de los trabajos más destacados sobre Félix de Urgell son Abadal i de Vinyals, R d'. 1949. La batalla del adopcionismo en la desintegración de la Iglesia visigoda: discurso leído en la recepción pública de Ramón de Abadal y de Vinyals en la Real Academia de Buenas Letras de Barcelona el 18 de diciembre de 1949 Barcelona: Real Academia de Buenas Letras de Barcelona; Abadal i de Vinyals, R d'. 1986. Catalunya Carolingia Vol. I Capítols sobre el Domini Carolingi a Catalunya Barcelona: Institut d'Estudis Catalans: 123-148; Perarnau i Espelt, J. 1997. «Feliu d'Urgell: fonts per al seu estudi i bibliografia dels darrers seixanta anys». Arxiu de Textos Catalans Antics 16: 435-482; Perarnau i Espelt, J. (coord.) 2000. Jornades internacionals d'estudi sobre el bisbe Feliu d'urgell. La Seu d'urgell, 28-30 de setembre de 1999. Crònica i estudis (Studia, Textus, Subsidia IX) Barcelona-La Seu d'urgell: Facultat de Teologia de Catalunya-Societat Cultural Urgel-litana; Perarnau i Espelt, J. (coord.) 1999. Feliu d'Urgell. Bases per al seu estudi (Studia, Textus, Subsidia VIII) Barcelona La Seu d'urgell: Facultat de Teologia de Catalunya-Societat Cultural Urgel-litana; Gil i Ribas, J. 2004. «Aproximació a l'adopcionsime de Feliu d'Urgell». Revista Catalana de Teologia: vol. 29, núm. 2, 335-395; Isla Frez, A. 2004. «El adopcionismo. Disidencia religiosa en la Península Ibérica (fines del siglo VIII-principios del siglo IX)». Clío \& Crímen 1: 115-134.

${ }^{18}$ Annales regni Francorum inde ab a. 741 usque ad a. 829, qui dicuntur Annales Laurissenses maiores et Einhardi, MGH, Scriptores Rerum Germanicum in usum scholarum separatim editi, F. Kurze (ed.), Hannover, 1895 (1950), año 792, 91-92; Abadal i de Vinyals, R d', 1986: 127; El autor sitúa esta consulta entre el año 786-790.

${ }^{19}$ Mansi, vol. 13, cols. 855 y sig.

${ }^{20}$ Mansi, vol. 13, cols. 884-906.

${ }^{21}$ Disertaciones, f. 22 r.
}

Hispania Sacra, LXIV

129, enero-junio 2012, 279-307, ISSN: 0018-215-X, doi: 10.3989/hs.2012.010 
En octubre de 1194, Alfonso el Trovador, rey de Aragón, conde de Barcelona y Marqués de Provenza, emitió un decreto de expulsión de los valdenses y todas las otras herejías anatemizadas por la Iglesia del territorio de la Corona de Aragón. ${ }^{22}$ Esta legislación prohibía a los vasallos del rey ayudar, esconder o encubrir herejes que tenían como plazo para salir libremente del reino hasta el 1 de noviembre, el día de Todos los Santos. Si al llegar la fecha no hubieran abandonado el territorio, serían detenidos y sus tierras confiscadas. El decreto estipulaba que cualquier persona podía infringirles el castigo, incluso la mutilación o la muerte. Los obispos y los gobernantes tenían que dar a conocer el decreto todos los domingos en las iglesias y, aquellos que no lo hicieran, podían incurrir en las mismas penas. Este decreto sentaba un precedente en la legislación contra la herejía en la Corona de Aragón. Centrado en los valdenses, también condenaba a todas las otras herejías entre las que se encontraba el catarismo y cuyo término estaba asociado al de herejía o heretica pravedad. ${ }^{23}$

«Dejaba ver este decreto que encontraba citado en varios autores y tuve finalmente la suerte de hallarlo entre las páginas que hizo el padre Mariana a las obras de Lucas Tudense ingeridas en la gran Bibliotheca de las PP. La hallé después igualmente extendido y en todo idéntico en la utilisima obra de Carlos Du Plessis d'Argentre De erroribus collectio». ${ }^{24}$

${ }^{22}$ Arxiu Capitular de Girona, pergamino original, armario III del claustro estantería A; Llibre Vert, f. 213; ed. del documento en EFV, 91-93; Marqués, J. 1962. «Alfonso el Casto y la seo de Gerona». VII Congreso de Historia de la Corona de Aragón, II, doc. 5, 218-219 Barcelona: Direcciones Generales de Archivos y Bibliotecas y de Relaciones Culturales; Baraut, C. 1996-1997. «Els inicis de la inquisició a Catalunya i les seves actuacions al bisbat d'Urgell (segles XII-XIII)», Urgellia 13, doc. 1, 419-420; Sánchez Casabón, A. I. 1995. Alfonso II Rey de Aragón, Conde de Barcelona y Marqués de Provenza. Documentos (1162-1196) «Fuentes Históricas Aragonesas», 23 Zaragoza: Institución Fernando el Católico-CSIC, doc. 621, 797-798; «Quapropter precedentium patrum nostrorum imitatores et sancte romane ecclesie canonibus obtemperantes, qui hereticos a conspectu Dei et catholicorum omnium abiectos ubique damnandos ac persequendos censerant, valdenses videlicet sive sabatatos, qui et alio nomine se vocant pauperes de Lugduno, et omnes alios hereticos, quorum non est numeros, a sancta ecclesia anathematizatos, ab omni Regno nostro et potestativo».

${ }^{23}$ Sobre la diversidad de nombres que recibieron los cátaros ver Thouzellier, Ch. 1969. «"patarins" et "albigenses"» en Ch. Thouzellier, Héresie et hérétiques: 204-262. Roma: Edizione di Storia e Letteratura; Duvernoy, J. 1973. «L'acception: 'haereticus' (iretge)='parfait cathare' en languedoc au XIIIe siecle», en W. Lourdaux, D. Verhelst (ed.), The Concept of Heresy in the Middle Ages (11th13th C.). Proceedings of the international conference, Louvain may 13-16: 198-210. Louvain: Leuven University Press; Duvernoy, J. 1975. «Une controverse su l'origene du mot Cathares: «Cathares» ou Ketter»?». Annales du Midi, vol. 87, num. 123: 341345; Biget, J.-L. 1998. «"Les Albigeois": remarques sur une dénomination», en M. Zerner (dir.), Inventer l'hérésie? Discours polémiques et pouvoirs avant l'Inquisition: 219-256 Nice: Collection d'Études Médiévales de Nice; Thery, J. 2002. «L'hérésie des bons hommes. Comment nommer la dissidence religieuse non vaudoise ni béguine en Languedoc? (XII ${ }^{e}$-début du XIVe s.)». Heresis 36-37: 75-117; Pegg, M. G. 2006. «Heresy, Good Men, and Nomenclature», en M. Frassetto (ed.), Heresy and the Persecuting Society in the Middle Ages: Essays on the Work of R. I. Moore: 227-239 Leiden: E. J. Brill.

${ }^{24}$ Disertaciones, f. $22 \mathrm{r}$. 
En este párrafo, Josep Mercader destaca dos de las fuentes principales que utilizó para documentar su lectura. La primera que menciona es la colosal obra del teólogo francés del siglo XVI, Margarin de la Bigne, Maxima Bibliotheca Veterum Patrum, publicada por primera vez en París entre 1575-1579 en 9 volúmenes y reeditada posteriormente en varias ocasiones. Por la referencia que especifica, Josep Mercader consultó la edición de Lyon de 1677 de 27 volúmenes que reproduce el decreto de la mano del jesuita Juan de Mariana en la introducción que hizo de las obras del obispo Lucas de Tuy. ${ }^{25}$ Mercader también menciona la obra del teólogo del siglo XVIII Charles du Plessis d'Argentre, quien escribió una recopilación de las herejías conocida como Collectio judiciorum de novis erroribus en $1728 .{ }^{26}$ Ambas obras reproducen el decreto íntegramente. También consultó, aunque lo especifique posteriormente para otros temas, la obra del teólogo del convento de Barcelona, Francisco Peña, que también reproduce el decreto en la edición del Directorium Inquisitorvm de Nicolau Eimeric. ${ }^{27}$ Todos estos autores relacionan la aparición del decreto con la valdesía y no con el catarismo.

Por otro lado, Josep Mercader no menciona que en 1198, Pedro, rey de Aragón y conde de Barcelona, ratificaba el mismo decreto ampliado y con varias especificaciones más. ${ }^{28} \mathrm{La}$ razón se debe a que en las fuentes documentales que consultó no integraron el decreto del rey Pedro. Mercader tampoco menciona la

\footnotetext{
${ }^{25}$ Bigne, M. de la, 1677. Maxima Bibliotheca Veterum Patrum, et antiquorvm scriptorum ecclesiasticorum: vol. 25, 190 Lugdvni; El fondo de Reserva de la Biblioteca Universitaria de Barcelona conserva la edición de Colonia de 1618-1622 que integra el decreto en el tomo 13, p. 230. Por el número de la página que indica Mercader, utilizó la edición de 1677.

${ }^{26}$ Plessis d'Argentre, C. du, 1728. Collectio judiciorum de novis erroribus qui ab initio duodecimi seculi post Incarnationem verbi usque ad annum 1713 Lutetiae Parisiorum: A. Cailleau, obra de 3 volúmenes; Sobre los valdenses ver el volúmen 1 «In quo exquisita monumenta ab anno 1100 usque ad annum 1542 continentur», 81-110. El decreto de Alfonso reproducido en la p. 83.

${ }^{27}$ Eimeric, N. 1578. Directorium Inquisitorvm: 64-65 del Libro II de la edición de Roma. Charles du Plessis conocía la obra de Eimeric y menciona que reproduce el decreto aunque utilizó, según especifica por la referencia, la edición del Directorium de Venecia de 1595.

${ }^{28}$ Original perdido; copia del siglo XIII-XIV en Arxiu Capitular de Girona, Cartulari de «Rúbriques Vermelles» del bisbe de Girona, num. 64, ff. 89v-90v (año del decreto 1197); Marca, P. de la 1688. Marca Hispanica sive limes hispanicus, París, doc. 487, cols. 13841385 (con fecha de 1197); Mansi, vol. 22, cols. 673-676; Flórez, E. 1819. España Sagrada, theatro geographico-historico de la iglesia de España, Madrid, vol. 43, doc. 52, 488-490, «ex archivo ecclesie Gerundensis» (mencionado en 1192); Tejada y Ramiro, J. 1861. Colección de cánones y de todos los concilios de la Iglesia de España y de América, en latín y castellano: vol. 3, 301-307 Madrid; Menéndez y Pelayo, M. Historia de los Heterodoxos españoles, Madrid: Biblitoeca de Autores Cristianos, 2006, vol. 1, 453-455 (original de 1880-1882); EFV, I, 93-94 (con la misma referencia de la España Sagrada); Baraut, C. 1996-1997: doc. 2, 420-422; Alvira, M. 2010. Pedro el Católico, Rey de Aragón y Conde de Barcelona (1196-1213) Documentos, Testimonios y Memoria Histórica: vol. 1, doc. 128, 265-268 Zaragoza: Instituto Fernando el Católico; Marquès i Planagumà, J. M. 2009. El Cartoral de Rúbriques Vermelles de Pere de Rocabertí, bisbe de Girona (1318-1324), edició a cura de J. de Puig Oliver, A. Serrat i Torrent, doc. 13 (64), 143-147 (Col. lecció Diplomataris-46) Barcelona: Fundació Noguera.
}

Hispania Sacra, LXIV

129, enero-junio 2012, 279-307, ISSN: 0018-215-X, doi: 10.3989/hs.2012.010 
obra que Lucas de Tuy escribió alrededor de 1236, para refutar las doctrinas de los herejes que pasaron por ciudades de la Corona de Castilla y que reproduce Juan de Mariana en el mismo tomo del decreto. La razón se deba probablemente a que el tratado contra los herejes de Lucas fue titulado por Juan de Mariana Adversus albigensium errores $\mathrm{y}$, en este caso, remitía a herejes cátaros más que valdenses. ${ }^{29}$

«Con el temor de estas penas pasaron a otros reynos muchos valdenses y enzapatados pues según refiere el citado du Plessis en tiempo de Ferdinando III rey de Castilla y León fueron en el año 1236 cazados algunos en Palencia, marcada su frente con hierro caliente». ${ }^{30}$

Los acontecimientos de Palencia a los que se refiere Mercader se encuentran descritos en una carta del 10 de agosto de 1236 de Gregorio IX. ${ }^{31}$ En ella el papa establece que Fernando III había promulgado un decreto contra los herejes que se aplicó en la diócesis de Palencia, cuyo castigo era dejar una marca en la frente con hierro candente, confiscación de bienes y el destierro de los acusados. La descripción de Mercader está extraída de la obra de Charles du Plessis que transcribe la carta de Gregorio. El autor francés atribuyó estos acontecimientos a los herejes albigenses. ${ }^{32}$

«Dilatado ya este error por varias provincias de Francia llegó a los oídos de Gregorio IX según refiere Eymeric la condena en el año 1238».33

\footnotetext{
${ }^{29}$ Lucas Tudensis, De altera vita, fideique controversiis adversus albigensium errores Libri III, edición a cargo de Juan de Mariana, Ingolstad, 1612; Juan de Mariana agregó el término Albigenses en el título que no constaba en el original; ver al respecto Falque Rey, E. 2009. «introducción». Lucae Tudensis. Opera Omnia cura et studio E. Falque Rey: LXVII-LXVIII Tomus II Turnhout: Brepols. El mismo tratado de Lucas fue editado por Jacobus Gretser un año después acompañado de otros tratados contra la valdesía con el título Lucae Tudensis episcopi, Scriptores Aliquot Succedanei Contra Sectam Waldensium, Ingolstad, 1613. El tratado editado por Mariana fue reproducido en la Magna Bibliotheca edición de 1618-22, vol. 13, 232 y sig. La edición de 1677 ampliada con más volúmenes y con el título Maxima Bibliotheca Veterum Patrum lo integra en el vol. 25, 277 y sig.; Sobre Lucas de Tuy y la herejía albigense ver Fernández Conde, F. J. 1978. «Albigenses en León y Castilla a comienzos del siglo XIII». León Medieval: doce estudios: 95-114; Palacios Martín, B. 1982. «La circulación de los cátaros por el Camino de Santiago y sus implicaciones socioculturales. Una fuente para su conocimiento». España Medieval 3: 219-230; Martínez Casado, A. 1983. «Cátaros en León, Testimonio de Lucas de Tuy». Archivos Leoneses 74: 263311; Fernández Conde, F. J. 1991. «Un noyau activ d'Albigeois en Léon au début du XIII siècle». Heresis 17: 35-51; Fernández Conde, F. J. 2005. La religiosidad medieval en España (siglos XI-XIII): 263265 y 410-413 Oviedo:Trea; Grau, S. 2012. Cátaros e Inquisición en los reinos hispánicos (siglos XII-XIV): 343-359 Madrid: Cátedra.

${ }^{30}$ Disertaciones f. 24

${ }^{31}$ Les Registres de Gregoire IX, ed. Lucien Auvray, París: Fontemoing, 1896-1907, vol 2, doc. 3271, 456.

${ }^{32}$ Plessis d'Argentre, C. du, 1728: 81.

${ }^{33}$ Disertaciones, f. 24.
} 
Dos años después del testimonio de Palencia, Josep Mercader describe una condena realizada por el papa Gregorio en 1238 que extrae del Directorium Inquisitorvm de Eimeric. ${ }^{34}$ El 9 de febrero de 1238 Gregorio escribió al obispo de Huesca para invitar al rey de Aragón a perseguir a los herejes conforme los estatutos de la Santa Sede ${ }^{35}$ y el 23 de abril hubo una primera iniciativa de inquisición en Navarra que afectaba también al territorio catalanoaragonés. ${ }^{36}$ El cronista de la orden de Predicadores Francisco Diago incorporó la noticia de Navarra y Pamplona cuando en 1238 se estableció la inquisición por los altercados que generaron «muchos herejes». De ellos se decía que «ciegos de su furor, dogmatizaban contra la libertad eclesiástica y las llaves del bienaventurado San Pedro». ${ }^{37}$ Con estas medidas el papa impulsaba la Orden de Predicadores para que realizara la inquisición en este territorio.

Además de esta condena, sabemos que en 1238 también hubo herejes en Burgos a través de la confesión del ciudadano Vidal de Arvival. El 25 de setiembre de 1238 el papa Gregorio IX notificaba al obispo de Burgos que investigara el grupo herético del que Vidal había mencionado formar parte. ${ }^{38}$ El inculpado llegó a la corte arrepentido por haber mantenido trato con los herejes, que, en este caso, se asimilan también al catarismo por sus vinculaciones con el comercio. ${ }^{39}$

«Algunos tenían varias dudas a la hora de actuar contra los herejes, sobre el modo de inquirir y formar el castigo de los referidos herejes y para establecer un método que sirviese de norma y regla común» [...] Por ello «determinaron juntarse en concilio y aclarar las dudas que les dividida, acordaron unánimemente y definieron los que debían refutarse herejes, la forma de inquirir y dar la sentencia, el modo que debía guardarse con los fautores, suspectos, relapsos y pusieron finalmente gran orden a todo lo perteneciente a este señorío». ${ }^{40}$

La siguiente noticia que transmite Mercader es el concilio celebrado en Tarragona en el año 1242. Si durante 1238 el Papa encargaba la tarea de la inquisición a las órdenes de predicadores e insistía en realizar la inquisición en Navarra y en el reino de Aragón, en el concilio de Tarragona de 1242 aparecía el primer manual para inquisidores. En este caso, la fuente que utiliza Mercader es la recopilación de concilios que realizó Josep Sáenz de Aguirre entre 1693 y 1694, publicada en Roma con el título Collectio Maxima Conciliorum omnium

\footnotetext{
${ }^{34}$ Eimeric, N. 1578: 769-770; Plessis d'Argentre, C. du, 1728: 98.

${ }^{35}$ Registres de Gregoire IX, vol. 2, doc. 4071, 881.

${ }^{36}$ Registres de Gregoire IX, vol. 2, doc. 4287, 979-80.

${ }^{37}$ Diago, F. 1599. Historia de la provincia de Aragon de la orden de predicadores desde su origen y principio hasta el año de mil y seiscientos: dividida en dos libros Barcelona: impressa por Sebastián de Cormellas en Santa Catherina martyr de Barcelona: fol. $7 \mathrm{~b}$.

${ }^{38}$ Registres de Gregoire IX, doc. 4526, 1135.

${ }^{39}$ Martínez Casado, A. 1983: 269.

${ }^{40}$ Disertaciones, f. 23 r.
} 
Hispaniae et novi Orbis ${ }^{41} \mathrm{El}$ concilio también fue transcrito en su totalidad en el Directorium de Eimeric ${ }^{42}$ y la referencia del concilio aparece en Charles du Plessis, ${ }^{43}$ ambas consultadas por el dominico.

El texto de 1242 era un Manual para inquisidores, o mejor dicho, para los obispos diocesanos que eran los encargados de emitir la sentencia. Este Manual era uno de los primeros que aparecía en Europa donde se catalogaba los distintos grados de pertenencia a la herejía y cómo había que proceder en las conversiones. ${ }^{44}$ Josep Mercader menciona los autores del texto; el obispo Pedro, del que no especifica más información, y Raymundo de Peñafort «con oficio de penitenciario del papa». ${ }^{45}$ El obispo era en realidad el arzobispo de Tarragona, Pedro de Albalat, autor de la Summa Septem Sacramentorum ${ }^{46}$ que presidió el concilio realizado entre finales de 1241 y principios de 1242 .

${ }^{41}$ Collectio maxima conciliorum omnium Hispaniae, et novi orbis epistolarumque decretalium celebriorum, edición a cargo de Josephi Saenz de Aguirre, Romae: Typis Jo. Jacobi Komarek Bohemi propè SS. Vicentium \& Anastasium in Trivio, 1694, vol. 3 págs. 498-501, § 74-100. Aguirre es la única de las fuentes documentales que consultó Mercader que integra el decreto del rey Pedro, (vol. 3, pp. 102-3) y en cambio no menciona el decreto de Alfonso.

${ }^{42}$ Eimeric, N. 1578: 169-162.

${ }^{43}$ Plessis d'Argentre, C. du, 1728: 102.

${ }^{44}$ Biblioteca nacional de Francia, fondo Doat, 36, ff. 226v241v; Otras copias manuscritas mencionadas por Antoine Dondaine se conservan en la, Biblioteca Dóle, ms. 109 (fols. 14r-18r), y otra copia en la Biblioteca nacional de Francia, lat. 14579, fol. 302 y sig. (copia del XV), en Dondaine, A. 1947. «Le Manuel de l'Inquisiteur (1230-1330)». Archivum Fratrum Praedicatorum 17: nota 40; Edición del documento en Eimeric, N. 1578: 234; Mansi vol. 23, cols. 553560; Saenz de Aguirre, J. 1694: vol. 3 § 74-100; Tejada y Ramiro, J. 1861: vol. 3, 351-357; Douais, C. 1899. «Saint Raymond de Peñafort et les hérétiques. Directoire à l'usage des inquisiteurs aragonais, 1242». Le Moyen Âge: vol. 12, 315-325; Valls i Taberner, F. 1929. «El Diplomatari de Sant Ramon de Penyafort». Analecta Sacra Tarraconensia 5: 254-261; Diplomatario, doc. 64, p. 74-82; Selge, K.-V. 1964. Texte zur Inquisition (Texte zur Kirchen und Theologiegeschichte, 4): 50-56 Gutersloh: Mohn; Baraut, C. 19961997: doc. 8, 429-434; Sobre el manual de la inquisición de 1242 ver Douais, C. 1899: 305-315; Dondaine, A. 1947: 96-97 y 131132; Cazenave, A. 1977. «Aveu et contrition. Manuels de confesseurs et interrogatoires d'Inquisition en Languedoc et en Catalogne (XIII-XIV s.)» en Actes du 99 Congrès National des Societés Savantes (Besançon, 1974), Section de philologie et histoire jusqu'à 1610, Tomo I: «La pieté populaire au Moyen Age»: 333-352 París; Mitre, E. 2005. «Herejía y «código» inquisitorial (algunas valoraciones actuales sobre la disidencia religiosa en el bajo Medievo)» en A. Guyance, P. Ubierna, Sociedad y memoria en la Edad Media, Estudios en homenaje de Nilda Guglielmi: 243-252 Buenos Aires: Consejo Nacional de Investigaciones Científicas y Técnicas, Instituto Multidisciplinario de Historia y Ciencias Humanas; Errera, A. 2002. «Il Directorium inquisitoriale di san Raimondo», en C. Longo (ed.) Magister Raimundus. Atti del Convegno per il IV centenario della canonizzazione di san Raimondo: 165-192 (Dissertationes Historicae, XXVIII) Roma: Institutum Historicum Fratrum Praedicatorum; Grau, S. 2012: 326-341.

${ }^{45}$ Disertaciones, f. 25.

${ }^{46}$ Linehan, P. 1969. «Pedro de Albalat, arzobispo de Tarragona, y su «Summa Septem Sacramentorum»». Hispania Sacra, 22: 9-30. 
El texto de 1242 empieza con la consultatio del arzobispo Pedro de la que Mercader integra algunos fragmentos extraídos de Saenz de Aguirre. ${ }^{47}$ El arzobispo expresaba la voluntad de continuar la inquisición contra la heretica pravedad iniciada por el obispo Berenguer de Barcelona en la misma ciudad que quedó interrumpida por la muerte del obispo. Allí se originaron dudas entre los juristas en el modo de proceder y para que procediera con más claridad en la investigación que se realizaría en la provincia de Tarragona, se daban estas directrices. ${ }^{48}$ Estamos, pues, ante un testimonio que nos remite a una posible inquisición iniciada por el obispo Berenguer II de Palou en Barcelona.

En realidad esto no era nuevo. El mismo obispo Berenguer había presenciado durante la década de los años 20 la abjuración de un matrimonio valdense. ${ }^{49}$ Josep Perarnau ha destacado que una versión manuscrita de la Summa de Paenitentia de Raymundo de Peñafort conservada en la Biblioteca Nazionale de Roma, integra una fórmula de abjuración contra valdenses realizada durante el obispado de Berenguer de Palou en la ciudad de Barcelona, concretamente durante el pontificado de Honorio, entre1216 y 1227. Éste sería un primer corpus legislativo, breve, que se situaría en un período donde aparecieron otros testimonios sobre la presencia de herejía en Cataluña. En marzo de 1217, el papa ordenaba al obispo de Urgel que procediera enérgicamente contra los herejes y sus encubridores que propugnaban errores en su diócesis. ${ }^{50}$ Poco después, entre 1218 y 1220, hay constancia de la presencia de herejes en las montañas de Prades que contó para su contención la actuación del arzobispo de Tarragona Espárrago de la Barca y los clérigos de Escala Dei. ${ }^{51}$ Estos acontecimientos de Prades eran asociados por el canónigo de Tarragona Joseph Blanc en 1739 con la herejía valdense. ${ }^{52}$

El texto del Manual tenía precedentes que Mercader no destaca. En 1232, el papa Gregorio IX promulgó la bula Declinante iam mundi en Espoleto en la que ordenaba al arzobispo Espárrago, y a todos los obispos de las diócesis catalanas

${ }^{47} 47$ Disertaciones, f. 25: «fray Raymundo de Pennaforti Poenitentiario Domini Papae et aliis prudentibus circa factum haeresis et inquisitionis de cetero siendae in Provincia Tarraconense clarus procedatur secundum discretionis», extraído, aunque no de forma correlativa, de Saenz de Aguirre, J. 1694: vol. $3 \S 74-75$..

${ }^{48}$ Diplomatario, doc. 64, 74.

${ }^{49}$ Perarnau i Espelt, J. 1992. «Fórmula d'abjuració d'un matrimoni de valdesos barcelonins». Arxiu de textos catalans antics 11: 331-346; Manuscrito conservado en la Biblioteca Nazionale de Roma, Codex 235: Continet primo Summam de Paenitentia et Matrimonio S. Raymundi de Pennaforti que incluye en un folio la Abiuratio doctrinae valdensium, f. 68a-b.

${ }^{50}$ Mansilla, D. 1965. La Documentación pontificia de Honorio III, 1216-1227: doc. 287, 218-219 Roma: Instituto Español de Historia Eclesiástica.

${ }^{51}$ Villanueva, J. 1851. Viage Literario a las Iglesias de España: Viage a Barcelona y Tarragona: vol. 19, doc. 42, 310-311 Madrid: Real Academia de la Historia.

${ }^{52}$ Biblioteca de Catalunya, ms. 312, Joseph BLANC, Arxiepiscopologi de la santa iglésia metropolitana de Tarragona, 1739, fol. 69r-69v.

Hispania Sacra, LXIV

129, enero-junio 2012, 279-307, ISSN: 0018-215-X, doi: 10.3989/hs.2012.010 
sufragáneas que procediesen contra los herejes y contra los que les protegiesen o les encubriesen de acuerdo con los estatutos promulgados por el mismo papa. ${ }^{53}$ Mercader tampoco menciona la asamblea eclesiástica reunida en Tarragona el 7 de febrero de 1234, donde el rey Jaime I promulgaba una constitución que sentaba las bases de la Inquisición medieval. ${ }^{54}$ Un año después empezaba a aplicarse las primeras medidas inquisitoriales en la provincia eclesiástica de Tarragona.

El 16 de mayo de 1235 el papa Gregorio IX encargaba al nuevo obispo de Vic, Bernat Calbó, juntamente con el prior de los dominicos de Barcelona y el hermano G. de Barbarano, que empezaran una inquisición en todas las casas religiosas del país, sin distinción de orden, sexo o edad. El objetivo era descubrir y corregir lo que fuera necesario en los lugares de la provincia eclesiástica de Tarragona sospechosa de la heretica pravedad. ${ }^{55}$ Esta inquisición pudo dar sus frutos ya que el 30 de abril del 1235 Gregorio IX mandaba una bula al arzobispo de Tarragona Guillermo de Montgrí sobre la penitencia que tenían que imponer a los herejes arrepentidos. ${ }^{56}$ Con la carta del papa se acompañaba otro texto de Raymundo de Peñafort sobre el modo de proceder contra los herejes de la provincia eclesiástica de Tarragona donde establecía una primera catalogación de los distintos grados de pertenencia a la herejía. ${ }^{57}$ Esta carta de 1235, conocida como la Nota Raimundi, era un precedente del manual de 1242. Josep Mercader no menciona ninguno de estos acontecimientos ya que no aparecen en las fuentes documentales que consultó. Estas disposiciones remiten a la herejía en general y no contemplan la referencia tan explícita sobre la valdesía como la que aparece en el concilio de 1242: «Concilium Tarraconense Ob Valdenses haereticos celebratum anno Domini MCCXLII».58

En este concilio, Raymundo de Peñafort establece que los herejes son los insabbatati (los valdenses) que sostienen que nunca debe jurarse, que no ha de obedecerse a las potestades eclesiásticas ni seculares, y que jamás debe aplicarse pena corporal..$^{59}$ En este Manual no aparece el término «cátaros», que no se utiliza en este tipo de fuentes, y los valdenses tienen un peso importante. A

${ }^{53}$ Carta 26 de mayo de 1232, edición en Baraut, C. 19961997: doc. 3, 422-423.

${ }^{54}$ Ed. en el códice colbertino, BNF, 362-366; Paris ex codicibus 277 y 1777 bibliotecae Colbertinae; Marca, P. de la 1688: doc. 511, cols. 1425-1428; Mansi, 23, 329-332; Tejada y Ramiro, J. 1861: vol. 3, 362-366; Baraut, C. 1996-1997: doc. 4, 423-425; Les Constitucions de Pau i Treva de Catalunya: segles XI-XIII. estudi introductori i edició a cura de Gener Gonzalvo i Bou. Textos jurídics catalans 9 , Barcelona, Generalitat de Catalunya, Departament de Justícia, 1994, 174-181.

${ }^{55}$ Registre de Gregoire IX, vol. 2, doc. 2360, 38. «faciendam in locis religiosorum Terraconensis provinciae»; Diplomatario, doc. 21, 32-33.

${ }^{56}$ Diplomatario, doc. 19, 29; Baraut, C. 1996-1997: doc. 5, 425-426.

${ }^{57}$ Carta 30 de abril de 1235; Diago, F. 1599: ff. 118-119; Diplomatario, doc. 20, 29-32; Baraut, C. 1996-1997: doc. 6, 426-428.

${ }^{58}$ Saenz de Aguirre, J. 1694: $§ 74$.

${ }^{59}$ Ibídem $\$ 76$. 
pesar de ello, las categorías que aparecen son aplicables a cualquier herejía. ${ }^{60} \mathrm{En}$ cambio sí que aparece la mención de buenos hombres y el término hereticos y heretica pravedad, dos conceptos que estaban asimilados a los herejes denominados cátaros. En realidad, a pesar de la mención de los valdenses en las fuentes que proceden de Cataluña, la presencia de cátaros era también una realidad tal y como constatamos con la declaración de Arnau Bretós, catalanus de Berga, acusado en 1244 de super crimine haeresis et valdensis. ${ }^{61}$ En su declaración, Arnau describe las comunidades cátaras que estuvieron en Cataluña durante la primera mitad del siglo XIII y destaca la presencia de cátaros entre 1242 y 1244 en Tarragona, Vall Porrera, ${ }^{62}$ las montañas de Siurana, ${ }^{63}$ y Castellverdú ${ }^{64}$

Mercader prosigue su disertación con la división de fautores, suspectos y relapsos, tal como aparece en el documento de 1242 e integra una fórmula para purgar a los sospechosos de herejía. La selección de este texto tampoco es arbitraria; Mercader transcribe la fórmula del documento de Raymundo de Peñafort que contiene la referencia más explícita para los errores valdenses ${ }^{65}$ para mostrar «que hubo en Cataluña la herejía de los enzapatados». ${ }^{66} \mathrm{~A}$ partir de ahora, su contenido se dedica a discernir sobre el origen del término enzapatados.

\section{SOBRE EL ORIGEN DE LOS VALDENSES}

«Los herejes pues conocidos con el nombre de ensabatados son una rama de los valdenses llamados con otro nombre Pobres de Lugduno. Traen la denominación de valdenses de su arquitecto Pedro Valdés o Valdense, ciudadano rico de Leona que era el nombre de la ciudad que ahora decimos Leon de Francia [...] La pobreza singular que seguían y profesaban dichos valdenses les dio el nombre de Pobres de Lugduno [...] La opinión más común y más fundada en declarar el origen de los valdenses es la que se halla al principio derivando su apelación de Pedro Valdés natural de León de Francia en donde comenzó a sembrar sus errores en el año $1170 »{ }^{67}$

Josep Mercader proporciona datos muy interesantes sobe el origen de los valdenses. El autor destaca que utilizó la información de Estevan de Bellaville.

${ }^{60}$ Dondaine, A. 1947: 96-97.

${ }^{61}$ Biblioteca Nacional de Francia, fondo Doat, vol. 24 ff. 182r192v; transcripción y edición del documento en Delcor, M. 1980. La société cathare en Cerdagne: nobles et bergers du XII ${ }^{e}$ au XIV siècle: 42-49 Tolouse: Imp. du Midi; Ventura, J. 1962. «El catarisme i valdesia als Països Catalans». VII Congreso de Historia de la Corona de Aragón: III, 132-134 Barcelona: Direcciones Generales de Archivos y Bibliotecas y de Relaciones Culturales.

${ }^{62}$ Doat, vol. 24, ff. 187r-187v.

${ }^{63}$ Doat, vol. 24, f. 187 r.

${ }^{64}$ Doat, vol. 24, f. 190 r.

${ }^{65}$ Dissertaciones, f. 26; Saenz de Aguirre, J. 1694: § 98: «Inzabbatatus, Valdensis, vel Pauper de Lugduno, nec haereticus in aliqua secta heresis per Ecclesiam damnata».

${ }^{66}$ Disertaciones, f. $23 \mathrm{v}$.

${ }^{67}$ Ibídem. 
Este autor, conocido como Esteban de Borbón, fue un inquisidor dominico de Lyon, que escribió alrededor de 1230 el Tractatus de diversis materiis Predicabilibus, un voluminoso tratado de predicación que recopila los acontecimientos producidos en Lyon durante los primeros años de Pedro Valdés. ${ }^{68}$ Mercader accedió al tratado de Esteban a través de la lectura de, teólogo dominico del Collegio Casanatense Tommaso Agostino Ricchini que fue editor y comentarista de la Summa Contra Catharos et Valdenses del teólogo italiano del siglo XIII Moneta de Cremona. ${ }^{69}$ Ricchini escribió las disertaciones sobre los valdenses, Dissertatio altera de Valdensibus, que preceden la obra de Moneta y fueron de gran utilidad para Mercader. ${ }^{70}$ El académico también consultó el mismo texto de Esteban de Borbón a través de la obra de Charles du Plessis que integra la parte del tratado de Esteban que está en relación con los orígenes de los valdenses y sus errores doctrinales. ${ }^{71}$

Existen varias fuentes que nos remiten a los orígenes de la valdesía. A través de ellas sabemos que Valdés (el nombre Pedro es posterior) era un ciudadano de Lyon, casado y con dos hijos que, en un momento de su vida, repartió sus bienes y se lanzó a predicar el Evangelio sumido en una pobreza absoluta. Esta conversión debió suceder en algún momento de principios de la década de 1170, según refieren las crónicas; quizás fuera en 1173 según la Crónica Anónima de Laon $^{72}$ o quizás en 1170, según el tratado de Esteban de Borbón. Josep Mercader se inclina por esta última referencia y sitúa el inicio de Valdés en el año 1170 fundamentándose en la lectura de Ricchini, ${ }^{73}$ y Charles du Plessis. ${ }^{74}$

«Dice [Esteban] habiendo oído a muchas personas contemporáneas a dicho Pedro, este hombre lleno de riquezas y simplicidad curioso de entender los evangelios la mando

\footnotetext{
${ }^{68}$ Stephani de Borbone, Tractatus de diversis materiis predicabilibus. Prologus-Liber primus. De dono timoris, J. Berlioz, J.-L. Eichenlaub (ed.) 2002 Turnhout: Brepols publishers; Stephani de Borbone, Tractatus de diversis materiis predicabilibus. Liber tertius. De eis que pertinent ad donum scientie et penitentiam, J. Berlioz (ed.), Turnhout: Brepols publishers, 2006; Sobre los valdenses también escribió el inquisidor Raniero Sacconi, «Summa de Catharis et Leonistis seu Pauperibus de Lugduno» en Dondaine, A. (ed.) 1939. Un traité néo-manichéen du XIIle siècle: Le Liber de duobus principiis suivi d'un fragment de Rituel cathare: 64-78 Roma: Istituto storico domenicano S. Sabina.

${ }^{69}$ Monetae Cremonensis adversus Catharos et Valdenses libri quinque, editado por Tommaso Agostino Ricchini, Roma, 1743. El manuscrito de Moneta es de 1250.

${ }^{70}$ De Ricchini son las Dissertatio altera de Valdensibus, p. 3648 integradas en el Adversus Catharos et Valdenses, que preceden a la obra de Moneta y divididas en 6 capítulos. Ricchini menciona el decreto de Alfonso de 1194 como testimonio de Catharis in Hispania, § 12 pp. 16-17.

${ }^{71}$ Plessis d'Argentre, C. du, 1728: 85-89 y 91-92.

${ }^{72}$ Chronicon Universali Anonymi Canonici Laudunensis ed. A. Cartellieri, W. Stechele, 1909 ParisLeipzig; Ex Chronico Universali Anonymi Laudunensis en MGH, Scriptores, XXVI, 442-457, especialmente pp. 447-8.

${ }^{73}$ Ricchini, T. A. 1743 : cap. 1 § 5-6.

${ }^{74}$ Plessis d'Argentre, C. du, 1728: 87.
} 
traducir a su lengua provenzal. La dio después a un clérigo de León que añadiese algunas sentencias a modo de glosa interlineal». ${ }^{75}$

Mercader también destaca la traducción en lengua vulgar que Valdés encargó de la Biblia y las autoridades. Esteban de Borbón menciona que Valdés contactó con un clérigo y un gramático para que tradujeran la Biblia en lengua vulgar a la que añadió fragmentos de los Padres de la Iglesia. ${ }^{76}$ Con él, predicaron hombres y mujeres, clérigos y laicos, hasta que el obispo de Lyon les prohibió que predicaran.

«privados de predicar y exponer las Escrituras recurrieron al papa Lucio III de quien tuvieron vehemente repulsa y confirmada sentencia del obispo lugdunense. Se obstinaron en su dictamen estos adictos y atraídos de la vana gloria que entre la rudeza y la austeridad negaron la obediencia del papa [...] Esta contumacia y rebeldía de comparecer al concilio Vernano a donde fueron citados fue causa de caer en nuevos errores. ${ }^{77}$

Valdés viajó a Roma en 1179 para presentarse ante el papa y legitimar su actuación. La hipótesis de Michel Rubellin sobre los primeros años de Valdés y sus relaciones con el arzobispo de Lyon arrojan nueva luz al respecto; según el autor, el grupo podría haber acudido al III concilio de Letrán por recomendación del arzobispo Guichard de Lyon, y el aprecio que el papa Alejandro III tenía del obispo puede ser la razón de que el papa no les condenara en $1179 .{ }^{78}$ Según el testimonio de Walter Map, que estuvo presente en el concilio de Letrán, el grupo de Valdés no fue mal recibido por el papa.$^{79}$ De este modo, los herejes condenados en el concilio de 1179 fueron los herejes «denominados cátaros, patarinos o publicanos», pero no en cambio los valdenses.$^{80} \mathrm{Al}$ año siguiente del concilio, en 1180, Valdés aparecía en el sínodo de Lyon $^{81}$ con una profesión de fe que definía

${ }^{75}$ Disertaciones, f. 24 r.

${ }^{76}$ Según Esteban de Borbón, Pedro Valdés encargo la traducción en 1170 «in vulgari, alteri ut scriberet quae ille dictaret, quod fecerunt: similiter multos Libros Bibliae, \& auctoritates Sanctorum multas per titulos congregatas, quas sententias appelabant» en Ricchini, T. A. 1743: cap. 1 § 5; Plessis d'Argentre, C. du, 1728: 87. En la Crónica Anónima de Laon no aparece el detalle de las traducción.

${ }^{77}$ Disertaciones, f. 24 v.

${ }^{78}$ Rubellin, M. 1998. «Au temps où Valdès n'etait pas hérétique: hypothèses sur le rôle de. Valdès à Lyon (1170-1183)» en M. Zerner (dir.), Inventer l'hérésie? Discours polémiques et pouvoirs avant l'Inquisition: 193-218 Nice: Collection d'Études Médiévales de Nice.

${ }^{79}$ Edición del tratado en Montague Rhodes J. (ed.) 1983. Walter Map. De Nugis Curialium (Courtiers'Trifles): Disertación 31: De Secta Valdesiorum, 124 y sig. Oxford: Clarendon Press; EFV, 121124.

${ }^{80}$ Mansi vol. 22, cols. 231-233, canon 27: «De hereticis: ... quos alii Catharos, alii Patarinos, alii Publicanos, alii nominibus vocant».

${ }^{81}$ Gastaldelli, F. (ed.) 1970. Goffredo di Auxerre: Super Apocalypsim Roma: Edizioni di storia e letteratura; Sobre Valdés ver el cap. XIV, De erroribus valdenses; EFV, 46-47.

Hispania Sacra, LXIV

129, enero-junio 2012, 279-307, ISSN: 0018-215-X, doi: 10.3989/hs.2012.010 
los preceptos de su comunidad que se caracterizaban por la ortodoxia religiosa frente la herejía dualista cátara. ${ }^{82}$

En el sínodo no hubo condena del arzobispo Guichard a Valdés y su grupo pudo predicar con cierta libertad en Lyon y sus alrededores. ${ }^{83}$ Pero en 1183 , con la llegada del nuevo arzobispo en Lyon, Jean Bellesmains, la situación cambió. El nuevo arzobispo expulsó a Valdés y a su comunidad de Lyon, denominados a partir de entonces Pobres de Lyon, y al año siguiente eran condenados oficialmente por el papa Lucio III en el Concilio de Verona con la epístola decretal $\mathrm{Ad}$ Abolendam diversarum haeresium pravitatem, del 4 de noviembre de 1184 que imponía anatema contra los cátaros, los patarinos, los que se llaman falsamente humillados y los pobres de Lyon, los josefinos y los arnaldistas ${ }^{84} \mathrm{Su}$ doctrina se expandió hacia otras regiones de Europa hasta llegar al sur de Francia. El teólogo Bernard de Fontcaude describía en su Adversus Waldensium sectam (ca. 1192) que alrededor de 1190 se produjo en Narbona una disputa entre el obispo de la ciudad y los valdenses. ${ }^{85}$ En 1194, eran condenados en la corona de Aragón por Alfonso el Trovador y muy poco después, los errores valdenses eran refitados doctrinalmente por el teólogo parisino Alan de Lille en su tratado De fide catholica ${ }^{86}$ Poco después, en 1203, aparecía el testimonio de un valdense en el norte de Cataluña. El clérigo A. de Puigverd juraba fidelidad al obispo Bernat de Urgell, y en su testimonio prometía no ayudar ni por palabra ni por obra a los herejes ni a los «inçabatats», uno de los pocos testimonios sobre herejía valdense. ${ }^{87}$ A finales del siglo XII la valdesía estaba presente en la región occitana y muy poco después en Cataluña.

${ }^{82}$ Liber Antiheresis de Durand de Huesca ed. Selge, K.-V. 1967. Die Ersten Waldenser, mit Edition des Liber antiheresis des Durandus von Osca: 3-6 Berlin: De Gruyter; EFV, 130-6. Sobre Durand de Huesca ver Dondaine, A. 1946. «Aux origines du Valdeisme: une profession de foi de Valdes». Archivum Fratrum Praedicatorum 16: 191-235; Dondaine, A. 1959. «Durand de Huesca et la polémique anti-cathare». Archivum Fratrum Praedicatorum 29: 228-277; Thouzellier, Ch. 1982. Catharisme et valdéisme en Languedoc à la fin du XII e et au début du XIII ${ }^{e}$ siècle Marseille: Laffitte Reprints; Papini, C. 2001: 204-221 y 252-259; Sarasa, E. 1981. «Duran de Huesca, un heterodoxo aragonés en la edad media», en Miscelania de Estudios en Honor de D. Antonio Durán Gudiol: 225-238 Sabiñánigo; Jiménez, P. 2008. Les Catharismes: Modèles dissidents du christianisme médiéval (XII ${ }^{e}$-XIII ${ }^{e}$ siècles) Renes: Presses Universitaires de Rennes; Smith, D. J. 2004. Innocent III and the Crown of Aragon. The Limits of Papal Authority: 231-260 Aldershot: Ashgate; Grau, S. 2009. «Durand de Huesca y la lucha contra el catarismo». Anuario de Estudios Medievales 39/1: 325; Smith, D. J. 2010. Crusade, Heresy and Inquisition: 137-170 Leiden: Brill Academic Press; Grau, S. 2012: 187-229.

${ }^{83}$ Rubellin, M. 1998: 210-214.

${ }^{84}$ Mansi vol. 22, cols. 492-493: «Catharos et patarinos, qui se Humiliatos vel Pauperes de Lugduno»; EFV, 50-3.

${ }^{85}$ PL vol. 204, cols. 793-840; EFV, 64-90.

${ }^{86}$ Alanus de Insulis, De Fide Catholica Contra Haereticos, ed. PL vol. 210, cols. 305-430.

${ }^{87}$ Baraut, C. 1992-1993. «Els documents, dels anys 11911200 de l'Arxiu Capitular de la Seu d’Urgell». Urgellia 11: doc. 1904, 69. 
Josep Mercader prosigue sobre el origen del nombre Valdés, una cuestión de la que existe un importante debate historiográfico..$^{88}$

«Algunos dicen que esta apelación de valdenses viene de la ciudad de Walden, que fue la cuna de estos errores situada en la frontera de Provenza. Otros la derivan de los valles que en las faldas, y raiz de los Alpes sirvieron de abrigo de estos fanáticos [...] Esta opinión aunque no declara el origen de la secta demuestra la conservación de un nombre y se halla favorecida con la memoria de los Barbitas». ${ }^{89}$

Sobre el origen del nombre, el autor destaca dos hipótesis al respecto; la ciudad «walden» (región de Vaud, cerca de Provenza) o uno de los «valles» que existen en la región de Lyon. Ambas hipótesis, sin mencionarlo directamente, son extraídas de Ebrard de Béthune, autor de un Liber Antiheresis escrito en torno a 1210, cuyos fragmentos sobre esta cuestión son reproducidos en las obras de Charles du Plessis y de Ricchini. ${ }^{90}$

Mercader destaca que la señal que llevaban en la parte superior de los zapatos y el uso del término «sabatas» con su lengua les dio el nombre de sabbatati o insabbatati, también mencionado por Ebrard de Béthune. ${ }^{91}$ Mercader explica que se llaman valdenses por su arquitecto, Pedro Valdés, y que la pobreza singular que seguían y profesaban les dio el nombre de Pobres de Lugduno. La crónica de Laon emplea el término Valdesius, ${ }^{92}$ el mismo que aparece en la profesión de fe que integra el Liber Antiheresis atribuido a Durand de Huesca. ${ }^{93}$ Otros autores como Gaufredo de Auxerre emplea el término Wandesius o Waudesius, ${ }^{94} \mathrm{y}$ el Liber Electorum, otra fuente valdense (1330-1350) también utiliza el término

${ }^{88}$ Gonnet, G. 1980. «Pierre Valdo ou Valdes de Lyon?». Bulletin de la Societe de l'Histoire du protestantisme française 126: 247-250; Gonnet, G. 1996. «Una “vexata quaestio“: il nome «valdese»». Bollettino della Società di studi valdesi 178: 88-92; Papini, C. 2001: 85-121; Biller, P. 2006. «Goodbye to Waldensianism?». Past and Present: 192/1, 3-33; Benedetti, M. (ed.) 2009. Valdesi medievali: bilanci e prospettive di ricerca Torino: Claudiana; Merlo, G. G. 2010. Valdo l'eretico di Lione Torino: Claudiana.

${ }^{89}$ Disertaciones, f. $23 \mathrm{v}$.

${ }^{90}$ Ebrard de Béthune, Liber Antiheresis edición en Bigne, M. de la, 1677: vol. 24, 1525-1584; Parte del texto en EFV, 143-152. Aunque no lo mencione, Mercader extrae la referencia de Ricchini, T. A. 1743: cap. 1, 1 «Alii a Civitate Walden quae in finibus Francia fita fuerit, ... sic appellatos putat, quod in Valle lacrymarum Convallium generali deinceps futura hac appellatione .... nomen Barbettis qui in subalpinis vallibus degunt tributum». La misma referencia del Valle en Plessis d'Argentre, C. du, 1728: 84 y Ricchini, T. A. 1743: cap. $1 \S 7$.

${ }^{91}$ Disertaciones, f. 23v; Ricchini, T. A. 1743: cap. 1 \$ , menciona los términos insabatati, Pauperes de Lugduno, Sabatati con los que son llamados estos herejes. Ricchini también destaca del tratado de Ebrard de Béthune Antiheresis «Quidam inquit qui vallenses se appellant... et etiam zabatenses a zabata, potius quan Christiani a Christo se volunt appellari. Sotulares cruciant, cum membra potius debeant cruciare, calceamenta coronant, caput non coronant».

${ }^{92}$ Supra, 72.

${ }^{93}$ Liber Antiheresis, 3 (ed. Selge, K.-V. 1967).

${ }^{94}$ Goffredo di Auxerre: Super Apocalypsim: 179 (ed. de Gastaldelli, F. 1970); véase para otras variantes de la traducción del término en Papini, C. 2001: 86-87.

Hispania Sacra, LXIV

129, enero-junio 2012, 279-307, ISSN: 0018-215-X, doi: 10.3989/hs.2012.010 
Waldis. ${ }^{95}$ Ante esta cuestión, Josep Mercader concluye que la opinión más común y más fundada es la que deriva el origen del término valdenses del apellido de su fundador, natural de Lyon. ${ }^{96}$ Mercader también menciona las relaciones entre valdenses y cátaros y destaca la región de Tolosa como centro de la herejía.

«Esta contumacia y rebeldía de comparecer al concilio Vernano a donde fueron citados fue causa de caer en nuevos errores y de coligarse en parte con los Albigenses que habían quedado en los confines de Tolosa». ${ }^{97}$

En determinadas ocasiones, cátaros y valdenses fueron confundidos con una misma herejía. Al mismo tiempo, Tolosa representaba para los cistercienses el nido de la herejía cátara y este territorio quedaba asociado con dicha herejía, acontecimiento que destaca Mercader. En realidad, varios cronistas de su convento proyectaban la idea de que la herejía llegaba a Cataluña desde Tolosa..$^{98}$ El fraile Pedro Marsilli de la Orden de Predicadores, instalado también en el convento de Barcelona, escribió alrededor de 1313 una traducción de la Crónica de Jaime I en la que dedicó unos fragmentos a la vida de San Raymundo de Peñafort y especificaba que:

«sentiens etiam fugitivos haereticos de Tholosanis, Bitterensibus et carcassonensibus partibus ad partes cathaloniae, velut ad secreti sinus latibulum, evolare, ac, more cancri, sermonem eorum serpere in plurium terrae partium ulcerosam corruptionem ... et obtineret inquisitiones hereticae pravitatis».99

Narcís Feliu de la Peña también planteaba la misma idea en 1709 al hablar de Ponce de Planella, «inquisidor de Urgel donde era mayor el mal por los Hereges de Tolosa, que se recogian en aquellos lugares». ${ }^{100}$

A continuación, el autor continua con su descripción de los acontecimientos y especifica que Valdés y los suyos no se sometieron al obispo que los denunció a causa de sus errores. Por esta razón fueron condenados en Roma por un conci-

${ }^{95}$ Biller, P. 2002. «The Liber Electorum» en P. Biller, The Waldenses, 1170-1530: Between a Religious Order and a Church: 207-224 Aldershot: Ashgate.

${ }^{96}$ Disertaciones, f. 23v; extraído de Plessis d'Argentre, C. du, 1728: 87: «Waldenses autem dicti sunt a primo huius haeresis auctore»; Ricchini, T. A. 1743: cap. 1 § 5: «Igitur a Petro Valdio, seu Valdensi originem appellationemque Valdenses duxere».

${ }^{97}$ Disertaciones, f. $24 \mathrm{v}$.

${ }^{98}$ Ver al respecto Biget, J.-L. 1998: 219-256; Brenon, A. 2003. «Les cisterciens contre l'hérésie» en A. Brenon, Les Archipels Cathares. Dissidence chrétienne dans l'Europe médiévale: 231-264 Cahors: Dire édition; Kienzle, B. M. 2001. Cistercians, Heresy and Crusade (1145-1229): Preaching in the Lord's Vineyard Woodbridge and Rochester, N. Y.: York Medieval Press-Boydell and Brewer.

${ }^{99}$ Edición del fragmento en Diplomario, p. 341. Ver al respecto Coll, J. M. 1949. «La crónica de Fr. Pedro Marsili y la «vita anonymi» de S. Ramón de Penyafort». Analecta Sacra Tarraconensia 22: 2150.

${ }^{100} \mathrm{Peña}$, N. F. de la, 1709. Anales de Cataluña y epílogo breve de los progressos, y famosos hechos de la Nación Catalana: 72 Barcelona: Joseph Llopis, Jayme Svrià y Juan Pablo Martí. 
lio posterior al de Verona, refiriéndose sin mencionar su nombre, al IV Concilio de Letrán de 1215 , en el que hay una condena explícita a la valdesía. ${ }^{101}$

«Subió a tan alto grado la presunción de su virtud que se hicieron lícitos absolver de pecados y negar esta facultad a quien no era tan pobre y penitente como ellos decían hay algunos en la Iglesia que no son ordenados de Dios ni de los hombres y estos son los legos malos $^{102}[\ldots]$ Otros son ordenados de los hombres y de esta clase son los malos sacerdotes. Otros finalmente son ordenados de Dios; ut boni laici qui servant mandata Dei, qui possunt ligare et solvere, et consecrare et ordinare; y de estos últimos se juzgaban estos infatuados, llevando todo su carácter o señal en los zapatos. Los demás errores que tenían cuando entraron a Cataluña estos enzapatados los refiere el citado concilio Tarraconense y el P. Eymerich en su Directorio». ${ }^{103}$

Josep Mercader describe algunos de los elementos doctrinales de los valdenses que fueron condenado por los teólogos católicos. Uno de los puntos fundamentales que menciona el autor se refiere a la negación de la facultad para absolver los pecados para aquellos sacerdotes que no siguieran la pobreza, reservándose esta facultad para aquellos ordenados por Dios, los valdenses. ${ }^{104}$ También especifica que los textos del inquisidor gerundense Eimeric y Raymundo de Peñafort describen los errores de los valdenses en Cataluña. En ambos documentos encontramos las referencias más explícitas sobre los errores de su doctrina que repercuten en territorio catalán.

«Derramados por España y Italia y perseguidos en todas partes estos errantes penitentes procuraban insinuar ocultamente sus errores pero no pudiendo reposar ni fijar el pie en ninguno de estos países se retiraron a dichos valles cuya aspereza y miseria fue la seguridad de su domicilio en ese inculto y áspero país que hicieron habitable a copia de trabajo y sudor. Demoraron por espacio de 3 siglos formando una especie de republica dirigida por los barbudos ${ }^{105}$ [...] Se llamaron así [Barbitas] porque el párroco o al cura (ahora llaman ministro) que les dirigía llevaba la barba larga y solían llamarse el barbudo de donde sus feligreses vinieron a llamarse Barbitas». ${ }^{106}$

El término Barba es el nombre que designa a los ministros valdenses a partir del siglo XIV. ${ }^{107}$ Este nombre se reservaba a los responsables de la comunidad

${ }^{101}$ Mansi vol. 22, cols. 986-990, cap. 3: De Hereticis; Sobre la condena del IV Concilio de Letran en Ricchini, T. A. 1743: cap. $2 \S 2$; cap. $3 \S 4$.

${ }^{102}$ Disertaciones, f. $24 \mathrm{v}$.

${ }^{103}$ Disertaciones, f. 25v. En este caso Josep Mercader destaca que para la cita en latín utilizó la obra de «Ricchini Disert. 2, 37»: ut boni laici qui servant mandata Dei, qui possunt ligare et solvere, et consecrare et ordinare.

${ }^{104}$ Sobre esta aspecto véase Cura Elena, S. del, 1983. «La potestad de consagrar la eucaristía en el proceso evolutivo de los valdenses medievales». Burgense. Collectanea Scientifica Burgos: 24, 95-191.

${ }^{105}$ Disertaciones, f. $25 \mathrm{v}$.

${ }^{106}$ Disertaciones, f. $24 \mathrm{r}$.

${ }^{107}$ Cameron, E. 2001: 183; Audisio, G. 1976 «Les barbes vaudois: XVe et XVI ${ }^{e}$ siècle». Bollettino della Società di studi valdesi 97/139: 65-75.

Hispania Sacra, LXIV

129, enero-junio 2012, 279-307, ISSN: 0018-215-X, doi: 10.3989/hs.2012.010 
cuya vida estaba vinculada al ministerio y a la absoluta pobreza. Charles du Plessis incorpora la referencia de Barbetas y Mercader extrae de la obra del autor francés todos estos elementos descriptivos. ${ }^{108}$ En este período, las comunidades más importantes se encuentran en los Alpes, entre el Piamonte y el Delfinado, y en la Provenza. En Cataluña no queda rastro de valdenses después del siglo XIV. Estas comunidades pervivieron hasta el siglo XVI cuando empezaron a establecerse los contactos entre los valdenses y las iglesias reformadas, el siguiente tema de Josep Mercader.

\section{LA FUSIÓN DE LOS VALDENSES CON LOS PROTESTANTES}

«San Vicente Ferrer el año de 1405 pasó desde el Delfinado a predicar a estos valles y en la carta que escribió el santo de la orden dice que había encontrado allí muchos catharos y otra rama de herejías las cuales le aseguraron que en el espacio de 30 años no habían visto ni oído otro predicador que de los herejes valdenses que desde la Puglia venían a predicar dos veces al año». ${ }^{109}$

Sin mencionarlo directamente, Josep Mercader aporta nuevas referencias documentales. Los acontecimientos que describe Mercader son extraídos de la carta que San Vicente Ferrer escribió al Maestro General de la Orden de Predicadores, Fray Juan de Puinoix, el 17 de diciembre de 1403. ${ }^{110}$ Después, el autor prosigue con las vinculaciones entre los valdenses y las iglesias reformadas.

«Esta denominación de valdenses se hizo común a los catharos y a todos los que en aquella región se declinaron de la verdadera creencia, aquí como la de los protestantes se ha hecho común y general a las de la religión que llamamos reformada, a las del cuerpo que dicen evangélica y a otras mas de 40 sectas, procedentes todas de Luthero y Calvino. Luego cuando la herejía de Calvino entró en los cantones [...] no dejaran piedra para mover a fin de atraer y agregar a su partido a los valdenses. ${ }^{111}$ [...] El arzobispo de Turín Caludio Seiseillo elevado de santo celo fue a visitarles en el año 1518 y habiendo inquirido de sus dogmas dejó escrito en su opúsculo Contra Valdenses que a excepción del anabolismo no eran muchos los errores que tienen. Desde la unión con los calvinistas serán sin duda en mayor numero porque aun siendo de la fe en los sectarios se varían y multiplican según

\footnotetext{
${ }^{108}$ Plessis d'Argentre, C. du, 1728: 103: A Quator ab hinc seculis waldenses in montibus et vallibus Sabaudiae ac Delphinatus delitescunt, et pastores suos barbas vocant: quapropter waldenses in istis regionibus vulgo nominatur, les Barbets.

${ }^{109}$ Disertaciones, f. $25 \mathrm{r}$.

${ }^{110}$ El texto sigue la Carta de San Vicente al Maestro General de la Orden de Predicadores, Fray Juan de Puinoix, 17-XII-1403, en Ferrer, San Vicente. 1996. Obras y escritos. Traducción del latín y edición de Adolfo Robles: 396 Valencia: Ayuntamiento de Valencia; Martín de la Hoz, J. C. 1998. «La conversión en la predicación de san Vicente Ferrer» Anales Valentinos 488: 363 y sig. La carta de Vicente Ferrer de 1405 del Delphinato es mencionada en Ricchini, T. A. 1743: cap. $5 \S 1$, aunque sin más información al respecto.

${ }^{111}$ Disertaciones, f. 25r-25v.
} 
el antojo y variación de sus ministros; como demuestra el clérigo Bossuet en la variación de las Iglesias Protestantes». ${ }^{112}$

En el siglo XVI los valdenses entraron a formar parte de la iglesia protestante de tradición calvinista. Protagonizaron este proceso el reformador francés Guillermo Farel y el arzobispo de Turín Claudio Seiseillo (Seyssel). Éste último escribió un tratado titulado Adversus Errores et sectam Waldensium ${ }^{113}$ que el autor del texto destaca. En este punto, Mercader también cita la lectura de la $\mathrm{Va}$ riación de las Iglesias protestantes ${ }^{114}$ del teólogo francés Jacques Benigne Bossuet como una de sus lecturas, sin olvidar la obra de Charles du Plessis del que aún podemos encontrar referencias en el texto sin que Mercader las destaque directamente. ${ }^{115}$

Jacques Bossuet describe, en el primer volumen de su obra, la herejía valdense. ${ }^{116}$ La obra de Bossuet, escrita en francés, conllevó una primera división del catarismo y la valdesía, después de una larga tradición en la que ambas herejías habían estado vinculadas como un mismo movimiento herético. La historia de la valdesía que escribió Bossuet fue de gran utilidad para Mercader como los acontecimientos de 1517 de Claudio de Seyssel. ${ }^{117}$

«Colocada en Ginebra la secta del calvinismo consiguieron sus ministros los cuales no habían podido tener los zwinglianos de Helvecia, pues en el año 1536 Guillermo Faralló [Farel] sagaz ministro de Ginebra se insinuó tan diestramente a los valdenses que les indujo a seguir su nueva secta y con esta conquista acrecentó el cuerpo de la facción del calvinismo [...] Mezclados ya los valdenses y confundidos con los errores de Calvino dejaron la pobreza y el carácter de sus primitivos enzapatados no habiéndoles quedado de su antigua secta otra cosa mas que el nombre de Barbotas». ${ }^{118}$

Tradicionalmente se estipula en 1532 cuando los valdenses adoptaron nominalmente la reforma. ${ }^{119}$ Josep Mercader destaca el año 1536 como la fecha en la que se produce la fusión de los valdenses con los protestantes. ${ }^{120}$ En 1536

\footnotetext{
${ }^{112}$ Disertaciones, f. $26 \mathrm{r}$.

${ }^{113}$ Scysselli, C. 1520 . Adversus errores et sectam Valdensium disputationes per quam eruditae ac piae Parisiis: in aedibus R. Chaudière; Ricchini, T. A. 1743: cap $1 \S 1$.

${ }^{114}$ Bossuet, J. B. 1688. Histoire des variations des eglises protestantes. Paris, 2 vols.

${ }^{115}$ Plessis d'Argentre, C. du, 1728: 105-107.

${ }^{116}$ Bossuet, J. B. 1688: vol. 2, 138-204; Bossuet menciona el decreto de Alfonso de 1194, pg. 142.

${ }^{117}$ Bossuet, J. B. 1688: vol. 2, 186-187; Bossuet menciona los acontecimientos que protagonizó Claudio de Seyssel en 1517, en Disertaciones, f. 26r.

${ }^{118}$ Disertaciones, f. $25 \mathrm{v}$.

${ }^{119}$ Ricchini, T. A. 1743: cap 2 \& , la unión de los valdenses con los calvinistas y protestantes; también cap. 1 § 4 la mención de que los valdenses derivaron en Calvino. Sobre este proceso de fusión ver al respecto Cameron, E. 2001: 240-253; Cameron, E. 1986. The Reformation of the Heretics: The Waldenses of the Alps, 1480-1580 Oxford: Clarendon Press; Gonnet, G. 1989. «L'internationale valdohussite». Heresis 13-14: 235-253.

${ }^{120}$ Ricchini, T. A. 1743 : cap $5 \S 6$. 
Francisco I promulgó el edicto de Coucy, mediante el cual se suspendían las persecuciones a los herejes durante seis meses. Poco después el rey francés invadía el Piamonte en su guerra contra Carlos V y expandía su influencia en dicha zona, lugar en el que se encontraban comunidades valdenses. Los dos acontecimientos permitieron un cierto clima de tolerancia y en este contexto, Guillermo Farel fue el gran promotor de la reforma a través del contacto con los ministros valdenses. ${ }^{121}$ En agosto de 1536 se celebró la confesión de Génova y la ciudad se declaraba oficialmente protestante en mayo de ese año. Guillermo Farel predicaba una versión del luteranismo que propiciaba las asambleas de fieles vinculada con la idea de una fe común y este espíritu impulsó, en octubre, la disputa de Lausanne, donde Calvino y Farel introducían conjuntamente la reforma en el territorio, según el modelo de Zwinglio. ${ }^{122}$

La noticia de la conversión de 1536 Mercader la extrae de la obra de Bossuet, quien explica cómo en Génova «los valdenses fueron consultados y fue entonces cuando comenzaron su sociedad con los calvinistas con las instrucciones de Farel, ministro de Génova». ${ }^{123}$ Esta misma información también la integra la obra de Charles du Plessis; el teólogo francés destaca la reunión de 1536 con la participación de Farel que propició la unión de valdenses y calvinistas. Este aspecto es el que destaca Mercader. ${ }^{124}$

\section{CONCLUSIONES}

«En una sola cosa convienen los herejes así antiguos como herederos y es en la manifiesta abierta rebelión a la comunión romana, en su desprecio a la tradición conciliar, en arrogarse la facultad de enseñar las escrituras, en copiar los ritos de la iglesia católica y en convivir con odio perpetuo al Pontifice. Esta son las armas con que defienden su religión los sectarios no pudiendo alegar razón ni fundamento que destruya la novedad de sus aserciones». ${ }^{125}$

En la disertación sobre los valdenses, Josep Mercader presenta información, fechas y acontecimientos que tuvieron gran trascendencia en la historia de la

${ }^{121}$ La relación de Farel y los valdenses en Provana de Collegno, Comte F.-X. 1887. «Rapports de Guillaume Farel avec les Vaudois du Piemont». Bulletin de la Société d'Études des Hautes-Alpes: 257-278; Martin, P. E. 1912. «Une lettre inedite de guillaume Farel relative aux vaudois du piemont». Bulletin de la societe d'histoire du protestantisme française 61: 204-213; Gonnet, G. 1986. «Les relations des vaudois des Alpes avec les réformateurs franco-suisses avant Calvin (1526-1533)» Croyances religieuses et sociétés alpines: Actes du Colloque de Freissinières, 15, 16 et 17 octobre 1981:165-178 Gap: Bulletin de la Société d'études des Hautes-Alpes.

${ }^{122}$ Ricchini, T. A. 1743: cap $5 \S 4$, las referencias de Calvino y Zwinglio; Ver también al respecto Ehrstine, G. 2002. Theater, culture, and community in Reformation Bern, 1523-1555: 55 Leiden: Brill.

${ }^{123}$ Bossuet, J. B. 1688: vol. 2, 353.

${ }^{124}$ Plessis d'Argentre, C. du, 1728: 107.

${ }^{125}$ Disertaciones, f. $26 r$. 
valdesía en territorio catalán y europeo. En el ámbito de la corona de Aragón, Mercader menciona el primer decreto de Alfonso el Trovador contra la herejía de 1194 y el concilio de 1242 que tuvo gran trascendencia en el marco inquisitorial.

El autor también presenta distintas hipótesis sobre el término valdense y, para hacerlo, recurre a las fuentes de la época recopiladas por Tommaso Ricchini y Charles du Plessis. Ricchini proporciona información muy útil sobre los valdenses como la crónica del siglo XIII de Esteban de Borbón. También utiliza la colección de herejías que escribió Charles du Plessis, ambas de gran utilidad por la gran cantidad de referencias sobre la valdesía, desde el siglo XII hasta el siglo XVI.

Para la fusión de los valdenses con los protestantes, Mercader utiliza, a parte de las dos obras anteriores, el tratado del teólogo Jacques Benigne Bossuet. La obra de Bossuet tiene un interés especial; es uno de los primeros tratados de gran erudición del siglo XVI escrito en francés. ${ }^{126}$ Bossuet dedica una parte al estudio de la herejía valdense y su análisis influyó mucho en las historias posteriores de este movimiento, como por ejemplo en el mismo Ricchini.

En este breve tratado encontramos reflejada la mentalidad característica de los cronistas de las órdenes de predicadores en relación a la herejía. La herejía se trató bajo los mismos parámetros de los teólogos que la combatieron en la Edad Media. La herejía es definida como un error y es comparada con una enfermedad que, «como cáncer», ${ }^{127}$ se expandía desde Francia hasta Cataluña. Esta concepción de la herejía, asimilada con una enfermedad, es el resultado de la construcción intelectual de los teólogos, polemistas e inquisidores del siglo XII al XIV que se ha mantenido por el gran peso de la historiografía católica en los estudios sobre la herejía. Esta concepción de la herejía estuvo presente en Francisco Diago, ${ }^{128}$ Francesch Camprubí ${ }^{129}$ o Pablo Vidal, ${ }^{130}$ entre otros. Los cronistas han vinculado la presencia de la herejía en Cataluña con la valdesía. Hemos mencionado el caso de Joseph Blanc para los acontecimientos de los años 20 del siglo XIII en Prades. Pero hay más; por ejemplo el fraile Sebastián Agustí Prats que recopiló en el siglo XVIII información sobre la inquisición realizada en la diócesis de Urgell de mediados del siglo XIII, que conocemos a través de la correspondencia entre Raymundo de Peñafort y el arzobispo de Tarragona. ${ }^{131}$

${ }^{126}$ Darricau, R. 1979. «De 1'histoire théologienne a la grande érudition: Bossuet (XVI-XVIII)». Cahiers de Fanjeaux 14, Historiographie du Catharisme: 85-118.

${ }^{127}$ Diago, F. 1599: fol. 7a.

${ }^{128}$ Supra nota 37.

${ }^{129}$ Supra nota 3.

${ }^{130}$ BU ms. 748: Pablo Vidal, Anales de la orden de Predicadores desde 1172 a 1624. Manuscrito del siglo XVIII.

${ }^{131}$ BU ms. 241: Sebastià Agustí Prats, Papeles manuscritos e impresos... OP de Barcelona; Manuscrito del siglo XVIII que reproduce la correspondencia de Raymundo de Peñafort sobre este asunto 
Sebastián Agustí imputó estos acontecimientos a la herejía valdense, aunque en realidad eran producto de la presencia de la herejía cátara tal y como constatamos con una encuesta realizada en 1250 en el pueblo de Gósol. ${ }^{132}$ Esta situación ha desplazado durante muchos años la herejía cátara a un segundo plano.

Josep Mercader preparó la disertación sobre los valdenses en la Real Academia de las Buenas Letras de Barcelona. En el siglo XVIII, el desarrollo de la Academia posibilitó la aparición de trabajos muy interesantes sobre la lengua y la historia de Cataluña. El ámbito cultural de la sociedad barcelonesa de mediados del siglo XVIII aun estaba caracterizado por las consecuencias que conllevó la derrota de 1714 y el papel de la Real Academia de las Buenas Letras de Barcelona fue, en este sentido, muy importante para proyectos vinculados con la historia, lengua y literatura de Cataluña, sobretodo cuando a partir de 1752, fue acogida bajo la protección de Fernando VI. El texto de Mercader se inscribe en este ámbito de estudio. Josep Mercader centra su disertación en el origen y desarrollo de la herejía valdense en Cataluña y su posterior fusión con el protestantismo y lo hace para mostrar el orígen de esta «actitud novedosa que cuestiona el rito católico». No hay que olvidar que Josep Mercader había sido prior del convento de Santa Caterina, el mismo convento donde se encontraba Raymundo de Peñafort y desde el cual se realizó una importante ofensiva contra la herejía cátara y valdense en el siglo XIII.

El autor escribe la disertación de los valdenses durante el reinado de Carlos III, una época donde las nuevas corrientes de pensamiento de la Ilustración, que aparecieron sobretodo en Francia e Inglaterra, representaban un peligro para el dogma de la Iglesia. La idea de trazar un vínculo entre las herejías medievales y modernas permite al autor establecer una continuidad entre los errores valdenses y protestantes. Y lo hace, principalmente, desde el estudio de la historia en el marco de la Academia más que de la teología. Todo esto hace de su disertación un texto documentado que recoge datos muy destacables de la historia de la valdesía a través de una importante base documental.

entre 1los folios 325-332. La correspondencia integra el prólogo: «Waldensium et Insabatatorum, seu Pauperum de Lugduno, qua cumfrater petrus de athenas Ord Pred Poncii de vilamur episcopi urgellensis inquisitore (eret) persequntur ad villas Puigcerdà et Berga atque ad Baronias de Josa et de Pinos, xe adhuc infecta episcopus urgellensis fuit per sedem apostolicam pontificalibus». Este mismo fragmento es el que Jaime de Villanueva reproduce en la primera carta del apéndice 28, Villanueva, J. 1851. Viage literario a las iglesias de España: Viage a Urgel: vol. 11, doc. 28, 231-232. Madrid: Imprenta de la Real Academia de la Historia.

${ }^{132}$ Sobre todo por la referencia a los «bos homes» y el ritual «pregaven Deu mans cubertes s'ajenolaven» que remiten a la herejía cátara. Edición del documento en Baraut, C. 1994-1995. «La presencia i la repressió del catarisme al bisbat d'Urgell (segles XIIXIII)». Urgellia 12: doc. 9, 512-513. 
BiBLIOGRAFÍA

\section{Fuentes manuscritas}

PP. Francesch Camprubí, Pere Màrtir Angles OP, Lumen Domus o Anals del Convent de Santa Catarina, Tom I des de l'any 1219 fins 1634 inclusive, 1743, Fondo de Reserva de la Biblioteca Universitària de Barcelona, ms. 1005.

Joseph Mercader OP, Disertaciones historico-eclesiasticas, Fondo de Reserva de la Biblioteca Universitària de Barcelona, ms. 837.

Joseph BLANC, Arxiepiscopologi de la santa iglésia metropolitana de Tarragona, 1739, Biblioteca de Catalunya, ms. 312.

Pablo Vidal, Anales de la orden de Predicadores desde 1172 a 1624, Fondo de Reserva de la Biblioteca Universitària de Barcelona ms. 748.

Sebastià Agustí Prats, Papeles manuscritos e impresos... OP de Barcelona; Fondo de Reserva de la Biblioteca Universitària de Barcelona, ms. 241.

\section{Fuentes impresas}

Les Constitucions de Pau i Treva de Catalunya: segles XI-XIII. Estudi introductori i edició a cura de Gener Gonzalvo i Bou. Textos jurídics catalans 9 Barcelona: Generalitat de Catalunya, Departament de Justícia 1994.

Abadal i de Vinyals, R. d', 1949. La batalla del adopcionismo en la desintegración de la Iglesia visigoda: discurso leído en la recepción pública de Ramón de Abadal y de Vinyals en la Real Academia de Buenas Letras de Barcelona el 18 de diciembre de 1949 Barcelona: Real Academia de Buenas Letras de Barcelona.

Abadal i de Vinyals, R. d', 1986. Catalunya Carolingia Vol. I Capítols sobre el Domini Carolingi a Catalunya: 123-148 Barcelona: Institut d'Estudis Catalans.

Aguirre, Josephi Saenz de, 1694. Collectio maxima conciliorum omnium Hispaniae, et novi orbis epistolarumque decretalium celebriorum, vol. 3 Romae: Typis Jo. Jacobi Komarek Bohemi propè SS. Vicentium \& Anastasium in Trivio.

Alvira, M. 2010. Pedro el Católico, Rey de Aragón y Conde de Barcelona (1196-1213) Documentos, Testimonios y Memoria Histórica 6 vols. Zaragoza: Instituto Fernando el Católico.

Audisio, G. 1976 «Les barbes vaudois: XVe et XVIe siècle». Bollettino della Società di studi valdesi 97/139: 65-75.

Auvray, L. 1896-1907 (ed.) Les Registres de Gregoire IX, 4 vols. París: Fontemoing.

Baraut, C. 1992-1993. «Els documents, dels anys 1191-1200 de l'Arxiu Capitular de la Seu d'Urgell». Urgellia 11: 7-160.

Baraut, C. 1994-1995. «La presencia i la repressió del catarisme al bisbat d'rgell (segles XII-XIII)». Urgellia 12: 487-524.

Baraut, C. 1996-1997. «Els inicis de la inquisició a Catalunya i les seves actuacions al bisbat d'Urgell (segles XII-XIII)». Urgellia 13: 407-438.

Benedetti, M. 2007. Donne valdesi nel medioevo Torino: Claudiana. 
Benedetti, M. (ed.) 2009. Valdesi medievali: bilanci e prospettive di ricerca Torino: Claudiana.

Biget, J.-L. 1998. ««Les Albigeois»: remarques sur une dénomination», en M. Zerner (dir.), Inventer l'hérésie? Discours polémiques et pouvoirs avant l'Inquisition: 219256 Nice: Collection d'Études Médiévales de Nice.

Bigne, M. de la, 1677. Maxima Bibliotheca Veterum Patrum, et antiquorvm scriptorum ecclesiasticorum: 27 vols., editado por Philippe Despont. Lugdvni apud Anissonios.

Biller, P. 2001. The waldenses 1170-1530: between a religious order and a church Aldershot: Ashgate.

Biller, P. 2006. «Goodbye to Waldensianism?». Past and Present: 192/1, 3-33.

Boletin de la Real Academia de las Buenas Letras de Barcelona, volúmen 9, núm. 65, 1917 Barcelona: Imprenta de la casa provincial de Caridad.

Bossuet, J. B. 1688. Histoire des variations des eglises protestantes. 2 vols. París: Sebastien Mabre-Cramoisy.

Brenon, A. 2003. «Les cisterciens contre l'hérésie» en A. Brenon, Les Archipels Cathares. Dissidence chrétienne dans l'Europe médiévale: 231-264 Cahors: Dire édition.

Cahiers de Fanjeaux, núm. 2: «Vaudois languedociens et pauvres catholiques», 1967.

Cameron, E. 1986. The Reformation of the Heretics: The Waldenses of the Alps, 14801580 Oxford: Clarendon Press.

Cameron, E. 2001. Waldenses: Rejections of Holy Church in Medieval Europe Oxford: Blackwell Publishers.

Campabadal, M. 2006. La Reial Acadèmia de Bones Lletres de Barcelona en el segle XVIII: l'interès per la història, la llengua i la literatura catalanes Barcelona: Reial Acadèmia de Bones Lletres de Barcelona; Publicacions de l'Abadia de Montserrat (Textos i Estudis de Cultura Catalana, 119).

Cazenave, A. 1977. «Aveu et contrition. Manuels de confesseurs et interrogatoires d'Inquisition en Languedoc et en Catalogne (XIII-XIV s.)» en Actes du 99 Congrès National des Societés Savantes (Besançon, 1974), Section de philologie et histoire jusqu'à 1610, Tomo I: «La pieté populaire au Moyen Age»: 333-352 París.

Coll, J. M. 1949. «La crónica de Fr. Pedro Marsili y la «vita anonymi» de S. Ramón de Penyafort». Analecta Sacra Tarraconensia 22: 21-50.

Cura Elena, S. del, 1983. «La potestad de consagrar la eucaristía en el proceso evolutivo de los valdenses medievales». Burgense. Collectanea Scientifica Burgos: 24, 95-191.

Darricau, R. 1979. «De l'histoire théologienne a la grande érudition: Bossuet (XVIXVIII)». Cahiers de Fanjeaux núm. 14 «Historiographie du Catharisme»: 85118.

Delcor, M. 1980. La société cathare en Cerdagne: nobles et bergers du XII ${ }^{e}$ au XIV siècle: 42-49 Tolouse: Imp. du Midi.

Diago, F. 1599. Historia de la provincia de Aragon de la orden de predicadors desde su origen y principio hasta el año de mil y seiscientos: dividida en dos libros Barcelona: impressa por Sebastián de Cormellas en Santa Catherina martyr de Barcelona.

Dondaine, A. (ed.) 1939. Un traité néo-manichéen du XIII ${ }^{e}$ siècle: Le Liber de duobus principiis suivi d'un fragment de Rituel cathare Roma: Istituto storico domenicano S. Sabina.

Dondaine, A. 1946. «Aux origines du Valdeisme: une profession de foi de Valdes». Archivum Fratrum Praedicatorum 16: 191-235. 
Dondaine, A. 1947. «Le Manuel de l'Inquisiteur (1230-1330)». Archivum Fratrum Praedicatorum 17: 85-194.

Dondaine, A. 1959. «Durand de Huesca et la polémique anti-cathare». Archivum Fratrum Praedicatorum 29: 228-277.

Douais, C. 1899. «Saint Raymond de Peñafort et les hérétiques. Directoire à l'usage des inquisiteurs aragonais, 1242». Le Moyen Âge 12: 315-325.

Duvernoy, J. 1973. «L'acception: 'haereticus' (iretge)='parfait cathare' en languedoc au XIII' siecle,» en W. Lourdaux, D. Verhelst (ed.). The Concept of Heresy in the Middle Ages (11th-13th C.). Proceedings of the international conference, Louvain may 13-16: 198-210 Louvain: Leuven University Press.

Duvernoy, J. 1975. «Une controverse su l'origene du mot Cathares: «Cathares» ou Ketter»?». Annales du Midi, vol. 87, núm. 123: 341-345.

Eimeric, N. 1578. Directorium Inquisitorvm, ed. F. Peña Romae: Populi Romani.

Errera, A. 2002. «Il Directorium inquisitoriale di san Raimondo», en C. Longo (ed.) Magister Raimundus. Atti del Convegno per il IV centenario della canonizzazione di san Raimondo: 165-192 (Dissertationes Historicae, XXVIII) Roma: Institutum Historicum Fratrum Praedicatorum.

Ehrstine, G. 2002. Theater, culture, and community in Reformation Bern, 1523-1555 Leiden: Brill.

Fernández Conde, F. J. 1978. «Albigenses en León y Castilla a comienzos del siglo XIII». León Medieval: doce estudios: 95-114.

Fernández Conde, F. J. 1991. «Un noyau activ d'Albigeois en Léon au début du XIII siècle». Heresis 17: 35-51.

Fernández Conde, F. J. 2005. La religiosidad medieval en España (siglos XIXIII) Oviedo:Trea.

Ferrer, San Vicente. 1996. Obras y escritos. Traducción del latín y edición de Adolfo Robles, Valencia: Ayuntamiento de Valencia.

Flórez, E. 1819. España Sagrada, theatro geographico-historico de la iglesia de Espa$\tilde{n} a$, vol. 43 Madrid: Imprenta de Collado.

Gastaldelli, F. (ed.) 1970. Goffredo di Auxerre: Super Apocalypsim Roma: Edizioni di storia e letteratura.

Gil i Ribas, J. 2004. «Aproximació a l'adopcionsime de Feliu d'Urgell». Revista Catalana de Teologia: vol. 29, núm. 2, 335-395.

Gonnet, G. (ed.) 1958. Enchiridion fontium valdensium 1, Du IIIe Concile de Latran au Synode de Chanforan (1179-1532) Torre Pellice: Claudiana.

Gonnet, G., Molnar, A. 1974. Les vaudois au moyen age Torino: Claudiana.

Gonnet, G. 1980. «Pierre Valdo ou Valdes de Lyon?». Bulletin de la Societe de l'Histoire du protestantisme française 126: 247-250.

Gonnet, G. 1986. «Les relations des vaudois des Alpes avec les réformateurs francosuisses avant Calvin (1526-1533)» Croyances religieuses et sociétés alpines: Actes du Colloque de Freissinières, 15, 16 et 17 octobre 1981: 165-178 Gap: Bulletin de la Société d'études des Hautes-Alpes.

Gonnet, G. 1989. «L'internationale valdo-hussite». Heresis 13-14: 235-253.

Gonnet, G. 1996. «Una «vexata quaestio»: il nome «valdese»». Bollettino della Società di studi valdesi 178: 88-92. 
Gonnet, G. (ed.) 1998. Enchiridion fontium valdensium 2, De la fin du XII ${ }^{e}$ au début du XIVe siècle Torino: Claudiana, 1998.

Grau, S. 2009. «Durand de Huesca y la lucha contra el catarismo». Anuario de Estudios Medievales 39/1: 3-25.

Grau, S. 2012. Cátaros e Inquisición en los reinos hispánicos (siglos XII-XIV) Madrid: Cátedra.

Isla Frez, A. 2004. «El adopcionismo. Disidencia religiosa en la Península Ibérica (fines del siglo VIII-principios del siglo IX)». Clío \& Crímen 1: 115-134.

Jiménez, P. 2008. Les Catharismes: Modèles dissidents du christianisme médiéval (XII ${ }_{\text {- }}$ XIII ${ }^{e}$ siècles) Renes: Presses Universitaires de Rennes.

Kienzle, B. M. 2001. Cistercians, Heresy and Crusade (1145-1229): Preaching in the Lord's Vineyard Woodbridge and Rochester, N. Y.: York Medieval Press-Boydell and Brewer.

Linehan, P. 1969. «Pedro de Albalat, arzobispo de Tarragona, y su «Summa Septem Sacramentorum»». Hispania Sacra 22: 9-30.

Lucae Tudensis 1612. De altera vita fideique controversiis adversus Albigensium errores libri III, nunc primum in lucem prolati, notisque illustrati a P. Joanne Mariana, S. I. Ingolstad.

Lucae Tudensis 2009. Opera Omnia Tomus II, cura et studio Emma Falque Rey Turnhout: Brepols.

Mansi, J. D. (ed.) 1759-1792. Sacrorum Conciliorum Nova Amplissima Collectio, 53 vols. Florencia-Venecia.

Mansilla, D. 1965. La Documentación pontificia de Honorio III, 1216-1227 Roma: Instituto Español de Historia Eclesiástica.

Marca, P. de la 1688. Marca Hispanica sive limes hispanicus ed. E. Baluze Parisiis: Franciscum Muguet.

Marqués, J. 1962. «Alfonso el Casto y la seo de Gerona». VII Congreso de Historia de la Corona de Aragón, II, 207-222 Barcelona: Direcciones Generales de Archivos y Bibliotecas y de Relaciones Culturales.

Marquès i Planagumà, J. M. 2009. El Cartoral de Rúbriques Vermelles de Pere de Rocabertí, bisbe de Girona (1318-1324), edició a cura de J. de Puig Oliver, A. Serrat i Torrent (Col.lecció Diplomataris-46) Barcelona: Fundació Noguera.

Martin, P. E. 1912. «Une lettre inedite de guillaume Farel relative aux vaudois du piemont». Bulletin de la societe d'histoire du protestantisme française 61: 204-213.

Martín de la Hoz, J. C. 1998. «La conversión en la predicación de san Vicente Ferrer» Anales Valentinos 488: 363-369.

Martínez Casado, A. 1983. «Cátaros en León, Testimonio de Lucas de Tuy». Archivos Leoneses 74: 263-311.

Menéndez y Pelayo, M. 2006. Historia de los Heterodoxos españoles 2 vols. Madrid: Biblioteca de Autores Cristianos.

Migne, J. P. (ed.) 1844-1855. Patrologiae Latinae, 271 vols. París, reed. Turnholti, Brepols, 1970.

Mitre, E. 2005. «Herejía y «código» inquisitorial (algunas valoraciones actuales sobre la disidencia religiosa en el bajo Medievo)» en A. Guyance, P. Ubierna, Sociedad y memoria en la Edad Media, Estudios en homenaje de Nilda Guglielmi: 243-252 
Buenos Aires: Consejo Nacional de Investigaciones Científicas y Técnicas, Instituto Multidisciplinario de Historia y Ciencias Humanas.

Merlo, G. G. 2010. Valdo l'eretico di Lione Torino: Claudiana.

Monetae Cremonensis 1743. Adversus Catharos et Valdenses libri quinque, editado por Tommaso Agostino Ricchini Romae: Ex Typographia Palladis, excudebant Nicolaus, et Marcus Palearini.

Montague Rhodes J. (ed.) 1983. Walter Map. De Nugis Curialium (Courtiers' Trifles) Oxford: Clarendon Press.

Palacios Martín, B. 1982. «La circulación de los cátaros por el Camino de Santiago y sus implicaciones socioculturales. Una fuente para su conocimiento». España Medieval 3: 219-230.

Papini, C. 2001. Valdo di Lione e $i$ «poveri nello spirito» Torino: Claudiana.

Pegg, M. G. 2006. «Heresy, Good Men, and Nomenclature», en M. Frassetto (ed.), Heresy and the Persecuting Society in the Middle Ages: Essays on the Work of R. I. Moore: 227-239 Leiden: E. J. Brill.

Peña, N. F. de la, 1709. Anales de Cataluña y epílogo breve de los progressos, y famosos hechos de la Nación Catalana Barcelona: Joseph Llopis, Jayme Svrià y Juan Pablo Martí.

Perarnau i Espelt, J. 1992. «Fórmula d'abjuració d'un matrimoni de valdesos barcelonins». Arxiu de textos catalans antics 11: 331-346.

Perarnau i Espelt, J. 1997. «Feliu d'Urgell: fonts per al seu estudi i bibliografia dels darrers seixanta anys». Arxiu de Textos Catalans Antics 16: 435-482.

Perarnau i Espelt, J. (coord.) 1999. Feliu d'Urgell. Bases per al seu estudi (Studia, Textus, Subsidia VIII) Barcelona-La Seu d'urgell: Facultat de Teologia de CatalunyaSocietat Cultural Urgel-litana.

Perarnau i Espelt, J. (coord.) 2000. Jornades internacionals d'estudi sobre el bisbe Feliu d'urgell. La Seu d'urgell, 28-30 de setembre de 1999. Crònica i estudis (Studia, Textus, Subsidia IX) Barcelona-La Seu d'urgell: Facultat de Teologia de CatalunyaSocietat Cultural Urgel-litana.

Plessis d'Argentre, C. du, 1728. Collectio judiciorum de novis erroribus qui ab initio duodecimi seculi post Incarnationem verbi usque ad annum 1713 Lutetiae Parisiorum: A. Cailleau.

Provana de Collegno, Comte F.-X. 1887. «Rapports de Guillaume Farel avec les Vaudois du Piemont». Bulletin de la Société d'Etudes des Hautes-Alpes: 257-278.

Rius Serra, J. 1954. San Raimundo de Penyafort. Diplomatario, Documentos, Cartas de San Raimundo de Penyafort, de Gregorio IX y de varios autores. Vida antigua, Crónicas, Procesos antiguos Barcelona (Diplomatario).

Rubellin, M. 1998. «Au temps où Valdès n'etait pas hérétique: hypothèses sur le rôle de. Valdès à Lyon (1170-1183)» en M. Zerner (dir.), Inventer l'hérésie? Discours polémiques et pouvoirs avant l'Inquisition: 193-218 Nice: Collection d'Études Médiévales de Nice.

Sánchez Casabón, A. I. 1995. Alfonso II Rey de Aragón, Conde de Barcelona y Marqués de Provenza. Documentos (1162-1196) «Fuentes Históricas Aragonesas», 23 Zaragoza: Institución Fernando el Católico-CSIC.

Sarasa, E. 1981. «Duran de Huesca, un heterodoxo aragonés en la edad media», en Miscelania de Estudios en Honor de D. Antonio Durán Gudiol: 225238 Sabiñánigo. 
Scysselli, C. 1520. Adversus errores et sectam Valdensium disputationes per quam eruditae ac piae Parisiis: in aedibus $\mathrm{R}$. Chaudière.

Selge, K.-V. 1964. Texte zur Inquisition (Texte zur Kirchen und Theologiegeschichte, 4) Gutersloh: Mohn.

Selge, K.-V. 1967. Die Ersten Waldenser, mit Edition des Liber antiheresis des Durandus von Osca Berlin: De Gruyter.

Smith, D. J. 2004. Innocent III and the Crown of Aragon. The Limits of Papal Authority Aldershot: Ashgate.

Smith, D. J. 2010. Crusade, Heresy and Inquisition in the lands of the Crown of Aragon (c.1167-. 1276) Leiden: Brill Academic Press.

Stephani de Borbone, Tractatus de diversis materiis predicabilibus. Prologus-Liber primus. De dono timoris, J. Berlioz, J.-L. Eichenlaub (eds.) 2002 Turnhout: Brepols publishers.

Stephani de Borbone. 2006. Tractatus de diversis materiis predicabilibus. Liber tertius. De eis que pertinent ad donum scientie et penitentiam, J. Berlioz (ed.), Turnhout: Brepols publishers.

Tejada y Ramiro, J. 1861. Colección de cánones y de todos los concilios de la Iglesia de España y de América, en latín y castellano, vol. 3 Madrid: Imprenta de Pedro Montero.

Thery, J. 2002. «L'hérésie des bons hommes. Comment nommer la dissidence religieuse non vaudoise ni béguine en Languedoc? (XII ${ }^{\mathrm{e}}$-début du XIV ${ }^{\mathrm{e}}$ s.)». Heresis 36-37: 75-117.

Thouzellier, Ch. 1969. ««Patarins» et «albigenses»» en Ch. Thouzellier. Héresie et hérétiques: 204-262. Roma: Edizione di Storia e Letteratura.

Thouzellier, Ch. 1982. Catharisme et valdéisme en Languedoc à la fin du XII et au début du XIII ${ }^{e}$ siècle Marseille: Laffitte Reprints.

Valls i Taberner, F. 1929. «El Diplomatari de Sant Ramon de Penyafort». Analecta Sacra Tarraconensia 5: 254-261.

Ventura, J. 1961-1962. «La valdesía de Cataluña». Boletín de la Real Academia de las Buenas Letras de Barcelona 29: 275-317.

Ventura, J. 1962. «El catarisme i valdesia als Països Catalans». VII Congreso de Historia de la Corona de Aragón: III, 132-134 Barcelona: Direcciones Generales de Archivos y Bibliotecas y de Relaciones Culturales.

Villanueva, J. 1851. Viage Literario a las Iglesias de España: Viage a Barcelona y Tarragona vol. 11 y 19 Madrid: Real Academia de la Historia. 